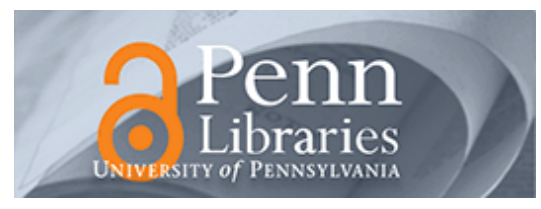

University of Pennsylvania ScholarlyCommons

$1-25-2010$

\title{
Systems Social Seience: A Design Inquiry Approach for Stabilization and Reconstruction of Social Systems
}

Barry G. Silverman

basil@seas.upenn.edu

Follow this and additional works at: https://repository.upenn.edu/ese_papers

Part of the Electrical and Computer Engineering Commons, and the Systems Engineering Commons

\section{Recommended Citation}

Barry G. Silverman, "Systems Social Seience: A Design Inquiry Approach for Stabilization and Reconstruction of Social Systems", Intelligent Decision Technologies 4(1), 51-74. January 2010. http://dx.doi.org/10.3233/IDT-2010-0069 


\title{
Systems Social Seience: A Design Inquiry Approach for Stabilization and Reconstruction of Social Systems
}

\author{
Abstract \\ This paper explores novel approaches under the design inquiry paradigm that promise to help \\ organizations better understand and solve socio-technical dilemmas. Design inquiry is contrasted with \\ scientific inquiry (Section 1). Section 2 presents a meso-scale model of models methodology for design \\ inquiry that synthesizes systems science, agent modeling and simulation, knowledge management \\ architectures, and domain theories and knowledge. The goal is to focus computational science on \\ exploring underlying mechanisms (white box modeling) and to support reflective theorizing and discourse \\ to explain social dilemmas and potential resolutions. Section 3 then describes an evolving agent \\ modeling and simulation testbed while Section 4 offers two gameworld applications that implement this \\ approach and that serve as an example of the new types of instruments useful for systems social \\ science. The conclusions wrapup by reviewing lessons learned about 10 criteria that have guided this \\ research.

\section{Keywords} \\ Social systems, systems approach, socio-cognitive agents, design inquiry

\section{Disciplines} \\ Electrical and Computer Engineering | Engineering | Systems Engineering
}


Intelligent Decision Technologies Journal (v.4, n.1, 2010, pp. 51-74)

\author{
Systems Social Science: \\ A Design Inquiry Approach for Stabilization and Reconstruction of Social Systems \\ Barry G. Silverman, PhD \\ Electrical and Systems Engineering Department \\ University of Pennsylvania, Philadelphia, PA 19104-6315 \\ basil@seas.upenn.edu \\ November 2008
}

\begin{abstract}
This paper explores novel approaches under the design inquiry paradigm that promise to help organizations better understand and solve socio-technical dilemmas. Design inquiry is contrasted with scientific inquiry (Sect. 1). Section 2 presents a meso-scale model of models methodology for design inquiry that synthesizes systems science, agent modeling and simulation, knowledge management architectures, and domain theories and knowledge. The goal is to focus computational science on exploring underlying mechanisms (white box modeling) and to support reflective theorizing and discourse to explain social dilemmas and potential resolutions. Section 3 then describes an evolving agent modeling and simulation testbed while Section 4 offers two gameworld applications that implement this approach and that serve as an example of the new types of instruments useful for systems social science. The conclusions wrapup by reviewing lessons learned about 10 criteria that have guided this research.
\end{abstract}

Keywords: social systems, systems approach, socio-cognitive agents, design inquiry

\title{
1) Introduction and Purpose
}

A number of papers have recently appeared warning of the "end of theory" (Anderson, 2008), the "end of science" (Horgan, 1996), and the end of social theory (Miles, 2001). The argument seems to hinge on the pace of change in a post-modern world, the proliferation of (internet) data, the power of modern computing, and the ability to automate mappings and forecasting of trends. With the famous example of Newtonian mechanics being replaced by Einsteinian relativity, in turn being replaced by quantum mechanics, we saw the decline of positivism and in some minds, the fracture of the scientific method. Further in the systems age where everything is interconnected and rapidly and continually changing in complex, unexpected ways, it is harder and harder to justify or take the time for reductive scientific method. Finally with the rise of big computing -omics and the "Googlification" of the world, there seems to be little need to reflect and understand theories, causality, or mechanism. Big pictures and trends can simply be derived.

In social systems, the argument appears strengthened given that the equivalent of "social genomes" are now appearing in the form of websites and newsfeeds from every ethno-political interest group around the globe. Sites exist that express almost every group's ideals, preferred states, grievances, and oppressive events they are enduring. These perspectives are available to be automatically scraped and the social genome maps to be computationally generated. Indeed computational scientists like King \& Lowe (2003) and Schrodt et al. (1994) have tools that automatically scrape and build such mappings - i.e., the Googlification of social dilemmas. Without understanding what is in these mappings we are able to compare them and model their trends - just as is done with DNA. In many fields of social science we can see 'black box' prediction models being formed off of similarly derived data sets with no one examining the content. This paper is not at all about the financial crisis, but the greatest consumers of black box 
modeling may be those producing the volatility forecasts and financial portfolio performance estimates that guide traders, banks, and investors. Once instruments are bundled for investors (e.g., mortgages, credit card loans, etc) it seems that few investors bother to check the situations and intentions of the actors actually involved (e.g, homeowners, student loanees, etc.). Instead the frenzied attention seems to focus on the volatility and statistical properties of the price when the market reacts to and trades those securities. Thus for example, the determinant of the next period forecast of the value of a security is largely its value in earlier periods - e.g., the influential JP Morgan "Risk Metric" relies on exponential smoothing of lagged variables; autoregressive conditional heteroskedasticity methods add in properties such as $2^{\text {nd }}$ moment of return volatility or prior time series distribution parameters (e.g., see Anderson et al, 2003); or Black-Scholes approaches that examine 'put and call' statistics (e.g., see Black and Scholes, 1973). Since they are absent any theory of the true mechanisms or underlying dynamics about those who must pay off the debt, such models are incapable of predicting watershed events not covered in the lagged variables they regress over. Also, even when they work, they can only predict but not explain social phenomena. Like the theorists listed at the outset, such black box modeling seems to foretell the end of social science. After all, who needs explanatory theories and mechanism investigations when we can predict and profit from the likely outcomes and trends in social systems? (Well at least most of the time.)

But failure to understand mechanism, at best, dooms one to having to be lucky to avoid mistakes. Failing to explore causality enslaves one to unexpected effects for any action undertaken. The current financial imbroglio and entering the Iraqi situation blindly are but two examples. An inability to penetrate beyond the surface may encourage one to do nothing since without greater insight, more often than not, further interventions will worsen the situation.

An alternative response possible to such an affront to reflection needs to be a "systems social science" that re-opens the dialog for inquiring into the design of social systems and for investigating it within a computational sphere. Fight fire with fire. The modern reflective approach, what I shall call Systems Social Science (SSS) can best be supported by computer simulation investigations that attempt to implement many theories into an open process (white box) where scientists, subject matter experts, and analysts can inspect designs, mechanisms, cause and effect, and operation-outcome explanations. If the social genomics are producing large, rapidly changing trend pictures, then systems social scientists need to delve into those big pictures with large computer arrays and computational science that easily support studies of the dynamics cutting across many reductive sub-disciplines in the social sciences. Thus they can potentially come to grips with synthesizing mechanism answers underlying big pictures and with exploring the current and future designs of a given social system.

In this view, computational social science is a systems or design topic. It's not just a black box statistical approach, but instead, a computer-based investigation of the synthesis of theories, expert knowledge, social genomic pictures and trends, and all other evidence and models. Of vital importance to this approach is (1) adopting best-of-breed theories from the social sciences (those that are descriptively valid); (2) keeping an openness to the wide array of systems methodologies and tools, whatever works best for implementing each theory (eg, adaptive agents, operations research, knowledge management systems, etc.); and (3) a design inquiry approach aimed at learning about a given social system. The point of such a synthesis is to better understand what unexpected effects emerge as a result of policy interventions in network-centric worlds where the social system is complex and poorly understood. This cannot be reliably done in the absence of social science, and not solely with social genomes and black 
box models. The point is that systems design is the methodological glue that can and must shift the fundamental science in this field.

This is a claim that how we approach the fundamental, underlying social sciences requires a paradigm shift, similar to the metamorphosis happening over the past half-decade to systems biology. However, it is not a claim that systems models that work in biological (or even mechanical) systems will work in social systems. In general, re-applying such models is a badly conceived idea and they won't work for long since social systems are fundamentally different from mechanical or even biological systems. They deserve their own form of causality and mechanism modeling. Many authors indicate that agent modeling is promising and potentially revolutionary for modeling social systems - it permits computational experiments and the study of emergence from micro-decision makers: e.g., Axelrod (1997), Axtell (1999), Bankes (2002), among others. However, this promise has not yet been fully realized. This paper reviews the dual purpose of how agent approaches might be strengthened and ways that social scientists and practitioners will need to shift their traditional paradigm if they are to take advantage of that promise.

\section{1) Current Social Science Paradigm}

According to many definitions, social science is immediately defined as a set of disciplinary silos. Here is a definition of social science from Answers.com:

1. The study of human society and of individual relationships in and to society.

2. A scholarly or scientific discipline that deals with such study, generally regarded as including sociology, psychology, anthropology, economics, political science, and history. Cioffa-Rivilla \& O'Brien (2007) concur but define it as the first five of these disciplines, omitting history as just the temporal dimension of each of the other five. Other definitions seem to add one or two disciplinary silos (e.g, geography, social studies, etc) or subtract them (e.g., the neuro-anatomy end of psychology that purports to be a natural science). But generally this is the accepted definition.

In addition, further sub-divisions and narrower specialties exist in each of these five or so major disciplines - typically one can identify up to half a dozen or more in each. For example, political science is often described as different methodological camps such as philosophy, electoral processes, institutional historians, rational decision theorists, and so on. Meta-analyses happen from time to time, but often within the camps, less often across camps, and rarely across disciplines. This appears to be the typical progression of a "normal science", flowing from the Scientific Method, its paradigm of reductive analysis and description of the world, and moving across the stages of maturation. University departments and journals have staked out territory in these different camps, faculties are growing, published papers increasing, jargon flourishes, specialized methodologies/methods/techniques still emerging, and the camps are growing ever deeper and narrower. Or in terms of Kuhn's The Structure of Scientific Revolutions, the social sciences appear to be enjoying a period of stable growth under their respective analytic paradigms, though Kuhn argues persuasively that the social sciences are pre-paradigmatic.

This brings up the question that Kuhn (1970), Popper (1965), and others encourage asking: Is good science happening, and can the science be improved? No benefit is to be garnered by impugning the alternative philosophic bases of reductive social science. Finding explanations and hidden, underlying mechanisms is the nature of inquiry in the social sciences and this relies on post-positivism, reflectivism, pragmatism, and other modern philosophies: eg, see Wight (2007). But this is the post-positivist era in the physical sciences as well. Instead, we 
ask this question particularly from the viewpoint of whether the social sciences can be improved by the introduction of systems engineering, of synthesis. The social sciences appear populated by a great many excellent scientists, those well aware of rigorous methodology, scientific inquiry, and the traditions of their respective sub-fields. In fact, as a modeler, one can't help but view the social science literature as a vast treasure trove of mostly qualitative models of greater or lesser validity. What can be improved, and the agenda I have been pursuing since 1999, is to comb the social science literature for useful human behavior and social theories and models, cull the bestof-breed theories and models, rate them on a validity assessment scale, map them into a readyfor-implementation mathematical pseudo-code, and place them in a repository (Silverman et al., 2001) for use in agent based modeling and simulation as Section 3 will explain. This approach turns the reductive theories into assets for the systems synthesizers.

\section{2) Social Systems}

The way universities, professional societies, and journals are organized, one may falsely conclude that the real world is similarly divided into these same parts. They lead us to believe there are economic problems, political problems, sociologic problems, marketing problems, engineering problems, and so on. Yet in today's world, all these are interconnected, and often serve only as different views of some underlying socio-technical problem. More than ever, we now live in the systems age, an era where all aspects of our society are interdependent.

E.A. Singer, Jr. (1959) argued that the mechanistic closed-system, physics-based, reductive thinking of the first half of the $20^{\text {th }}$ century (the machine age) is not readily adapted to the systems age, where open systems interact and lead to waves of repercussions on personal and organizational value systems. A unique challenge of social systems is that there are many subsystems that are themselves purposeful systems -- many levels of self-determining functionality, from the depths of the cognitive up to the heights of the economic institutions and political strategies -- and one must find ways to encapsulate them in hierarchies or networks, so that different levels may be meaningfully studied. This network of teleologic sub-systems, this independent purposefulness of the parts, is the distinguishing trait of social from other types of systems. It means that social systems are the hardest ones, the most complex - what are referred to as ill-structured and having "wicked” dilemmas.

Rittel \& Webber (1973) offer the seminal paper defining “wicked” problems and how social dilemmas (and hence attempts to apply scientific solutions) in the social sciences differ from how science works in the natural sciences. Social problems are never solved, only re-solved over and over. They have no definitive formulation and one must examine multiple perspectives to begin to understand them. Wicked problems have no stopping rule, and often are symptoms of other problems. The best solutions may be those that facilitate multiple, individual agendas. Ackoff (1994) calls these problems "messes" and suggests idealized designs where the dissolution of problems outweighs other approaches such as satisficing, optimizing, and so on.

\section{2) "Systems Social Science” Paradigm Emerges}

A direct complement of the reductivist paradigm of the Scientific Method is the so-called synthetic paradigm which forms the core of systems science. This paradigm is also called the systems approach, an approach that seeks to study how holisms work, and how the whole is more than the sum of its parts (synergy). Analysis seeks to reduce a system or systems problem to its parts, and to study each part in isolation. Synthesis, alternatively, is the process of learning about 
(1) the independent teological functionality or purposefulness of the parts including their own micro-decision processes. The parts have a functionality that needs to be accurately captured and encapsulated, though precision of a part's inner workings is less important than studying the whole (accuracy vs. precision). (2) Provided a part's functionality is adequately captured, interrelation between the parts is of prime importance. This is the expansionistic study of interconnectedness and interdependencies.

Systems thinking dates to early man (e.g, the Egyptian Pyramids and before). The systems approach as an area of study, however, came about during the mid $20^{\text {th }}$ century as the result of work on many individuals on systems theory such as Bertalanffy, Mead, Shannon, Weiner, and others. Systems thinking flourished for a couple of decades, but seemed to recede in prominence during the mid 70s. However, in the last decade the field has seen a resurgence as people try to come to grips with netcentricity, network science, and complex and emergent phenomena. In particular, scientists and engineers are trying to understand "systems of systems" and "families of systems" and how they differ from the more traditional view of systems. Thus an airplane may be a system (and it typically has a clear hierarchy of management, operation, and ownership), but an airport handles numerous airlines' fleets of airlines and can be thought of more properly as a system of systems each of which is managed, operated, and owned by different stakeholders who must collaborate, cooperate, and provide services for each other if the airport is to be an effective enterprise: e.g., see Jamshidi (2009). Likewise, a family or coalition of systems may be even more loosely connected, and these may even compete and/or conflict with each other as in the case of say drug smugglers trying to use the airports and circumvent the law enforcement system, or communities seeking to work out conflicts with use of resources and the environment: eg., Sage (2007), Hipel (2007). The SoS field has stimulated new avenues of research into numerous unanswered questions concerning definitions, requirements, designs, modeling \& simulation, control and adaptivity, openness and emergence, and service-oriented behaviors. There are new journals, annual conferences, and a growing literature on the SoS phenomenon. It is, however, a literature heavily fueled by a logistics orientation and much of it is aimed at how should sociotechnical enterprises manage “man-made” systems.

There is no real reason to limit the SoS approach to man-made systems, and in fact social systems are man-made as well (and woman-made). My concern here, can be thought of as an extension to the SoS and family of systems thinking for social SoS. For that purpose, an important branch of the systems field for was the Singer/Churchman/Ackoff group and their work on what Singer referred to as the Experimentalism School of Thought, though most others label it as a branch of Pragmatism. The most thorough overview of that school and its roots may be found in Britton \& McCallion (1994), though a full account is in Ackoff \& Emery (2006).

Singer believed in "sweeping in" of multiple perspectives to continually reshape and improve the questions being investigated. He applied that approach to the sciences, but due to failing health, ran out of time to apply it to further fields. As a result he was criticized by those not in the sciences for failing to have considered their perspectives - e.g, politics, religion, morals, etc. (interview 2008). Churchman (1971) responded and wrote a seminal book on an inquirer architecture which is an organization that, at the highest levels, would continually improve and adapt by following the Singerian or Experimentalist mode of thinking. He suggested "sweeping in" the "outside" viewpoints of other fields that may be thought of as the enemies of science (eg, morality, theology, politics, etc.) when trying to get a broader systems solution, though he did not provide an explicit method for doing so. Ackoff (1974), in turn, developed a methodology known as the Interactive Planning process, a process that addresses the pursuit of ideals and that 
covers feelings, all relevant knowledge, and "outside" (of science) viewpoints since it includes those individuals as participants. It particularly is aimed at determining and executing "idealized designs" for social adaptation, transformation, and ongoing development, where the community and/or organizational stakeholders are engaged to determine the idealized design or end state and means to reach it.

The Experimentalists thus provide a rich leaping off point that we shall explore in this article for helping to guide inquiring organizations, as well as groups, regions or states trying to transition to some form of improved protections, services, and ideals.

What seems clear is that social science is often reductive and theoretical, and generally not aimed at implementation. Systems and SoS engineering, while synthetic and pragmatic, is often devoid of the theoretical, especially theory from the social sciences. These two are complementary approaches and can each benefit and evolve by embracing the other. By harnessing both of them within a Singerian inquirer framework, we may be able to accomplish a broad and deep capability. This is not just a sketch of a support system, but an evolving, adaptive testbed we are constructing for advancement in both fields and in systems social science itself.

Churchman (1971) defined systems thinking for social organization designs from the epistemologic perspective of various philosophers. Inquirer architectures are the theoretical and epistemological basis of organizations and decisionmaking aimed at learning and adapting in order to continually dissolve or (re)solve social dilemmas. The most sophisticated of these is the Singerian Inquirer Systems, As mentioned earlier, Churchman pointed out the need to sweep in other perspectives (those outside of science), though he never did that himself. My own methodology for doing so is described in the next section. This continues and extends the Singerian inquirer framework into a computational methodological dimension.

Figure 1 - Singerian Inquirer and Idealized Design Architecture for Learning Organizations Agent \& Model Based

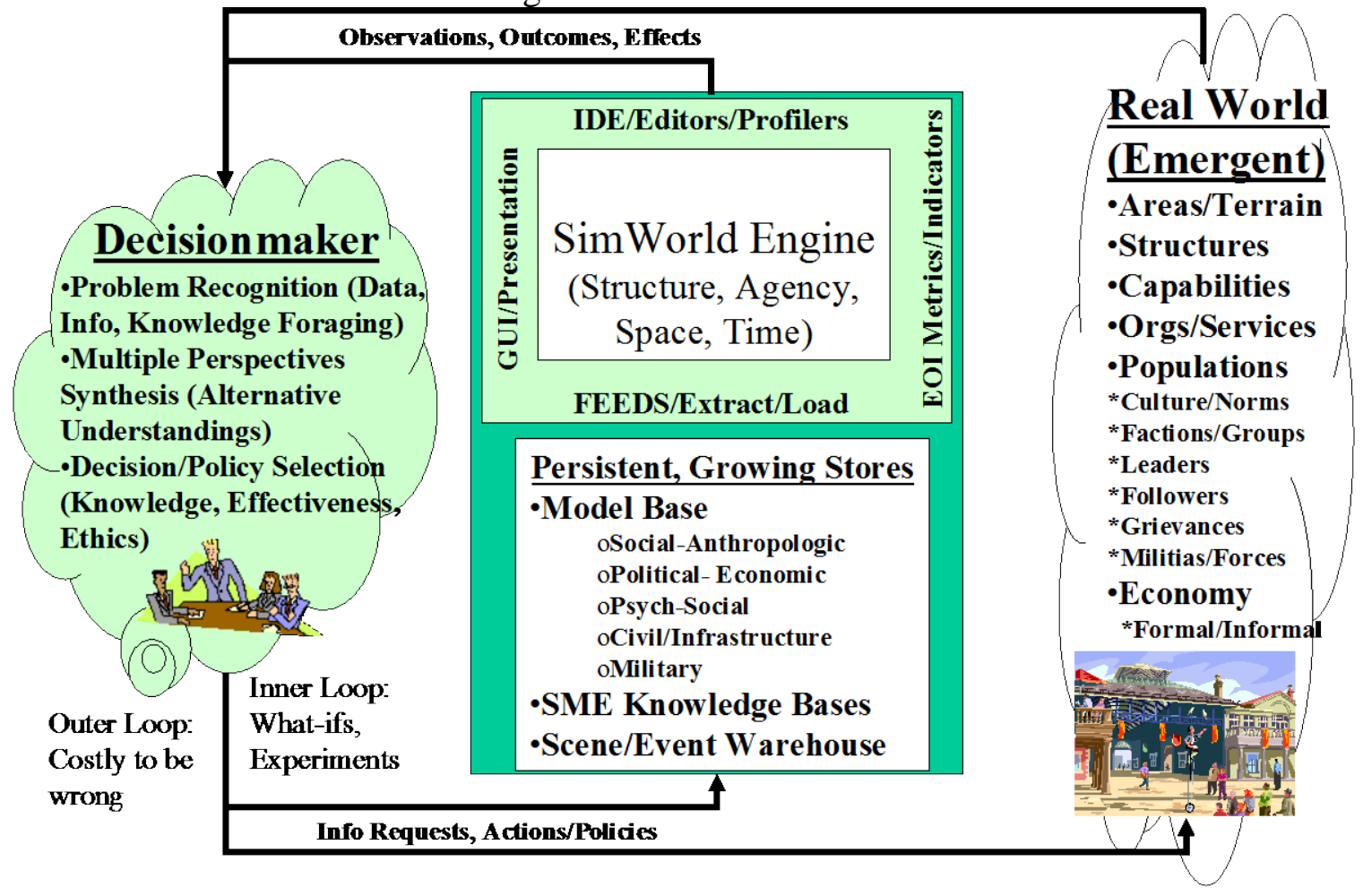


Figure 1 depicts the Singerian Inquirer notion. It shows a real world, emergent social system on the right and an inquirer organization and set of decisionmakers on the left. In the middle is some sort of knowledge management and decision support system - in this case its illustrated as containing a simulated or virtual world that uses agents, and models to capture what is learned about the social system (but more on that shortly). A Singerian Inquiry organization is similar to a Singerian Inquirer since its an adaptive organization that tries to learn about and make sense of the social situation, is open to multiple perspectives, adopts society and humanity as its client (omnicompetence), and forages for new knowledge from distributed sources. Inquirer organizations realize that there often is only one try to implement a successful policy in the real world, so they move back and forth between refining higher orders of measurement (for ethical treatment of the client) and sweeping in change from outside forces to further extend knowledge. Finding an answer to the current question often becomes less important than finding a better question.

A literature and emerging set of practices has sprung up in the design of learning organizations, adaptive information systems, and knowledge management communities that make use of and extend Churchman's ideas: e.g, Mason \& Mitroff (1973), Courtney, Haynes \& Paradice (2007). Consistent with Courtney (2001) and Hall et al (2007), we extends these ideas to a design of an Inquirer decision support system where decisionmakers are aided by a mental model of the social system that helps to elucidate the differing perspectives. This paper further extends the notion of the Singerian inquirer for "systems social science" by addressing design criteria for tools that will be useful in the center of Figure 1 as reviewed in the next section. This design should be aimed not only at helping decisionmakers and clients (all stakeholders) of an inquiring organization, but also at attempting to provide a new (systems) pathway for social science investigations. It should be noted that the design criteria are intended to be continually re-asked in the effort to further advance the frontier of these types of tools. Thus, answers obtained and judged to be reasonable today, will soon be out of date and the questions will bear re-asking and re-answering as social science advances.

\section{3) Methodology for a Meso-Level Model of Models}

The questions of most interest in network science and the modeling of stability and reconstruction of netcentric organizations lie at the intersection of social and cognitive research and auger for a socio-cognitive architecture to serve as the testbed for advancing the science. Such an architecture, to be effective, also must encompass the organizations, resources, and infrastructure that the individuals are supported by, as indicated in the previous section. One way to view the modeling task is as shown in Figure 2. That includes an extensible model of models architecture where cognitive, social, and experimentation layer models and tools all can be plugged in or out as needed for the region being studied. The "glue" for synthesizing the many models together involves a common middleware that all models translate into when they wish to publish outputs or subscribe to inputs. This middleware glue is sometimes called a serviceoriented architecture since many of the models are peer-to-peer and need to provide services for each other. The middleware also facilitates synchronous as well as asynchronous components plus it exposes the APIs needed by each of the peer models in the collection if and when they wish to invoke each others' functionality or services. In our implementation of this middleware, when a new model is placed in the proper directory), it automatically shows up in the configuration manager where the designer can then select or deselect when to utilize it. Further, 
all its input parameters should be scanned and made available for design of experiments automatically by the Monte Carlo model controller.

Figure 2 - Meso-Scale Socio-Cognitive Model of Models Testbed Architecture and Methodology

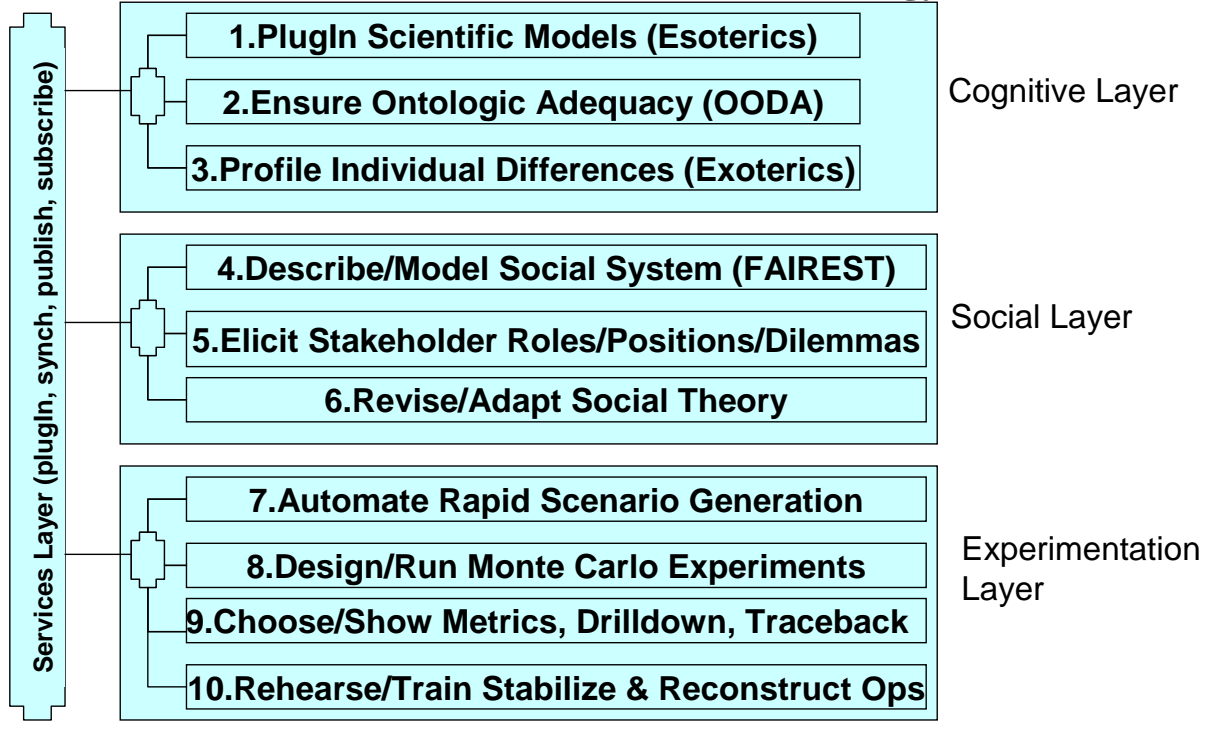

Figure 2 shows 10 boxes which also are the steps (and criteria questions) of the methodology for adding and using models in the meso-level testbed collection. These correspond to 10 criteria discussed in the remainder of this Section, but before discussing those, it is useful to first note the point of this architecture is that one can scale up to 100 s or possibly 1,000s of cognitive agents who fill the roles of the groups and organizations modeled in the social layer. There are many possible ways to engineer such a collection. Sun [1] and Zacharias et al. [2], however, provide a useful survey of the respective fields of social agents and cognitive agents and show that there are very few environments that straddle both topics to provide a sociocognitive architecture. Specifically, the social agents field is based on the notion of achieving scale (10,000s of agents) using very simple agents (eg, a few rules) to illustrate how emergent macro-behaviors might arise (e.g., these include toolsets such as Sugarscape, Repast, Swarm, and various cellular automata). These social agent systems present compelling simulations that do illustrate and mimic interesting phenomena (spread of messages, segregation, hidden identities and tension due to threat of violence, etc.). However, they offer no ability to explain the microdecision making, the inner cognitive processes at play. Cognitive agents (e.g, ACT-R, Soar, etc.), by contrast, offer the ability to model inner processes in great detail, but typically these don't scale to more than a very few agents interacting in a team. Further, very few of the cognitive agent architectures satisfy the 3 criteria in the cognitive layer of Figure 2, as we will discuss. Nevertheless, one could conceivably plug them and the well known multi-agent social models togther. To date, we have gone a different route, but there is no reason why any well known and well-understood agent system could not be added to the meso-scale architecture we have delineated here. Doing so could be a useful way to study the differences and relative strengths and weaknesses of different approaches. Indeed, Section 4.1 shows one such effort.

A survey of the literature at this writing reveals three meso-scale architectures currently available, each of them offering very different, but nicely complementary capabilities - the 
PMFserv/FactionSim one discussed here, the multi-agent dynamic-network (MADN) from Carnegie Mellon, and COnflict Modeling, Planning and Outcomes EXploration (COMPOEX) from BAE Systems. The MADN simulation places agents in social and cognitive networks that co-evolve as the agents interact and engage in various activities. In contrast to traditional multiagent models, the agents are constrained and enabled by their position in a network of networks. Those networks and the individuals within them both adapt, leading to resiliency and behavior which is a function of both agent and network properties: e.g., see McCulloh \& Carley, 2008. The MADN agents fail to fully satisfy the criteria for cognitive agents as they are not capable of independent reasoning outside of their network-driven belief updates. However, they provide a robust approach to modeling the networks of the social layer (criterion 4) and the adaptivity of those networks (criterion 6). The MADN framework and models are thus of interest and we hope to explore how they complement the PMFserv-FactionSim socio-cognitive agents in the future.

Similarly, we have just begun a funded grant to plugin the COMPOEX meso-scale framework and are excited about its complementary features as well. Specifically, COMPOEX was originally envisioned as a model of models approach where different modeling paradigms (eg, systems dynamics, Bayesian networks, agents, etc.) would be applied as befits the application in the stabilize and reconstruct space: Kott \& Carpac (2008). Ultimately, it evolved into an architecture similar to Figure 2 and straddling eight models (power structure, military, economy, infrastructure, agriculture, civil population, media, and insurgents): Waltz (2009). Due to its large size (over 10,000 variables), it fails criterion 7 and currently is not easily assembled for a new region. Further, its size and the determinism of most of its models (system dynamics) lead to it rarely being used in experimentation mode (criterion 7). However, its strength lies in the breadth and depth it brings to the modeling of the social system (criterion 4) and tools it includes for evaluation of progress and drilldown and traceability of outcomes back to inputs (criterion 9). We expect these would augment the capabilities of the PMFserv-FactionSim capability described in this article.

The major hurdle facing anyone who attempts a meso-scale architecture is that there are no scientific theories (and certainly no first principles) about what to model and how models inter-relate. For example, how do memes migrate? How do people convey norms? How does alternative media and messengers play a role or not at the micro-processing level (and how does this differ upon each type of listener)? Why are some groups happy in impoverished conditions while others rebel? What is the correct theory behind terrorism (sacred values, religious extremism, genocide, patrimonialism, poverty, jealousy, mimicry and copying of fashionable but deadly youth movements, etc, etc.)? There are innumerable questions like these that have no single answers. The result is that a scientific and social system testbed must be assembled and each alternative competing hypothesis must be studied. Real world social systems and cases need to be recreated in the gameworlds and improved over time as new evidence is uncovered. Only by studying the real world cases (and sharing them across investigators) can we advance the science in this arena. The breakthrough we hope to occur from this effort will happen only with a meso-scale, socio-cognitive agent framework that can serve as a theory testbed to study the intersection of psychological and sociological theories and phenomena. Continually seeking answers to the 10 criteria questions discussed below is one way to proceed.

\section{1) Cognitive Layer: Sweeping in Behavior Theory and "The Enemies"}

Singerian Inquirer organizations are aimed at creating exoteric knowledge, or knowledge

for broad social problems. This contrasts with finding esoteric, or scientific, knowledge such as 
reductive social science that applies to smaller and smaller domains as it is refined (Churchman, 1971). It is ironic that Singer's focus on exoteric knowledge to the exclusion of esoterics may in fact lead to the very trap mentioned at the outset of this paper - the death of science. Singer lived before the computational era, and could not have foreseen the impact of the -omics, Googlification, black box models and abilities to project social system trends without the need to understand their causes. He would not have approved.

Churchman felt the solution to the Singerian science bias was to sweep in the enemy or outside perspectives brought about by morality, emotions/feelings, religion, and so on. He did not want to eliminate science, but to enrich and broaden the perspectives one investigates with a scientific mind. It is perhaps doubly ironic that the breakthrough my lab has pioneered and followed for about a decade sweeps in the "enemies" of Singer's scientific exoteric approach largely via the aid of reductive and esoteric knowledge. Specifically, there is no reason to ignore the esoteric knowledge of the social sciences. We synthesize and integrate and test it along with the exoteric via socio-cognitive agent mind-body models that can readily combine them. As the reader will see, these extensions are intended to provide both a representation to capture and store all the different perspectives, and a way to simulate how people might react as different interventions and transformations are attempted. This result is intended as a virtual social system where one can study what ideas lead to improvement in the ideals. It is a set of instruments for decision makers to try out their policies on simulated versions of the stakeholders, and make their mistakes in that space, before they attempt solutions in the real world. The research on these instruments is ongoing, but has matured to where these tools are field tested and fielded, a point that will be covered in what follows.

The description is cast as a series of criteria questions that one can ask oneself if trying to improve on the design. This discussion will proceed bottom up since the agent paradigm permits one to do that. We begin with an overview of performance moderator functions (PMFs). A PMF is a micro-model covering how human performance (e.g., perception, memory, or decisionmaking) might vary as a function of a single factor (e.g., sleep, temperature, boredom, grievance, and so on.). My lab's agent software, PMFserv, synthesizes over 100 best-of-breed PMFs within a unifying mind-body framework and thereby offers a model of models where micro-decisions lead to the emergence of macro-behaviors within an individual. None of these PMFs are "homegrown"; instead they are culled from the literature of the behavioral sciences. Since the science is expected to advance, these PMFs are replaceable. Users can turn on or off different PMFs to focus on particular aspects of interest. Thus we continually re-ask:

Criterion 1: Did the Modelers Survey and Implement Best-of-Breed PMFs? - Did the researchers find and implement the current best-of-breed underlying theory and micro-model (eg., PMF) affecting a given aspect of human psycho-social behavior?

The unifying architecture in Figure 3 shows how different subsystems are connected. For each agent, PMFserv operates what is sometimes known as an observe, orient, decide, and act (OODA) loop. PMFserv runs the agents perception (observe) and then orients all the entire physiology, personality/value, and social relations subsystems to determine levels of fatigues and hunger, injuries and related stressors, grievances, tension buildup, impact of rumors and speech acts, emotions, and various mobilizations and social relationship changes since the last tick of the simulator clock. Once all these modules and their parameters are oriented to the current stimuli/inputs, the upper right module (decision-making/cognition) runs a best response algorithm to try to determine or decide what to do next. The algorithm it runs is determined by its stress and emotional levels. 
As an illustration of one of the modules in Figure 3 and of some of the best-of-breed theories that PMFserv "sweeps in", let us consider "cognitive appraisal” (Personality, Culture, Emotion module) - the bottom left module in Figure 3. This is where an agent (or person) compares the perceived state of the real world to its value system and appraises which of its values are satisfied or violated. This in turn activates emotional arousals. For the emotion model, we have implemented one of several found in the literature as described in Silverman et al (2006a). An essential step of this methodology is thus to survey the literature, isolate best-ofbreed theories and models, and select and implement one or more of them. This is a methodology described more fully in Silverman et al. (2001), including scales for assessing the "internal validity" of a given PMF, as well as a decision theoretic formalism for implementing the PMFs into a common formalism and pseudo code.

Cognitive appraisal theory serves as an example of Criterion 1 since it is the state-of-theart understanding of how we apply our values, how emotions arise, and what types of choices that leads us toward. However it quickly brings us to our second criterion. Specifically, the literature review turned up several reasonable models for cognitive appraisal, and we chose the most implementable of those -- what is known as the OCC model (Ortony, Clore, Collins, 1998). The OCC model requires a value system - labelled as goals, standards, and preferences (GSPs). However, the OCC model provides little insight into how to define GSPs and no details on how to model them.

Criterion 2: Is the model collection ontologically adequate? - Any theories or models brought from the reductive side of social science will need to be synthesized with other theories and models, and gaps must be identified and filled in if the agent is to be workable.

This criterion is consistent with the earlier definitions of a system as having teleologic subsystems and, in turn, being part of a supra-system. We should thus expect to wind up with a field of micro-theories, and the need for a framework for synthesizing them. The discussion above about an OODA loop that synthesizes many of the PMFs is a good example of this at the individual agent level. In the next section we will examine a higher level synthesis that brings many agents together into social systems. There is also the need for synthetic frameworks within each module or subsystem of the agent as we will examine in the next paragraph. First though, it is worth pointing out that this is generally a problem of assessing the "ontologic adequacy" of the collection. While a given PMF may have a relatively high internal validity, when we bring it together with others into a larger behavioral framework, what overall gaps are found, what inadequacies exist, and how does this alter the original micro-model?

To continue the emotion example, the OCC model needs one to implement a person's value system. It requires every agent to have goals, standards, and preference (GSP) trees filled out. One way to do this is to draw from the field of decision science, or more specifically, one can conceptualize GSP trees as multi-attribute value structures where each tree node is weighted with importance weights. One can synthesize still further and state, a Preference Tree represents an agent's long-term desires for world situations and relations (for instance, no weapons of mass destruction, an end to global warming, etc.) that may or may not be achieved within the scope of a scenario. The Standards Tree defines the methods an agent is willing to employ to attain his/her preferences. Standards constrain actions and are also the way agents judge the actions of others. The Standard Tree nodes could embrace all of civil, military, and religious doctrine. However, we find it sufficient to merge several best-of-breed personality and culture profiling instruments - these worked well for the many leaders and followers we have built from around the world. Finally, the Goal Tree covers short-term needs and motivations that drive progress toward 
preferences. In the Machiavellian (Machiavelli 1988) and Hermann-profiled (Hermann, 1999) world of leaders, the Goal Tree reduces to the duality of growing/developing versus protecting the resources in one's constituency. Expressing goals in terms of power and vulnerability provides a high-fidelity means of evaluating the short-term consequences of actions. For nonleader agents (or followers), the Goal Tree also includes traits covering basic Maslovian type needs and Positive Psychology factors. In summing this up, in one paragraph we have discussed the synthesis of numerous social science theories, models, instruments, and definitions. These all combine in order to make one purposeful subsystem of the agent, a subsystem that can be parameterized to profile an actual individual's motivational or value structure. That subsystem is also a "calculator" of behavior and choice, one that can be run autonomously.

Figure 3 - PMFserv - a Social-Cognitive-Affective Architecture

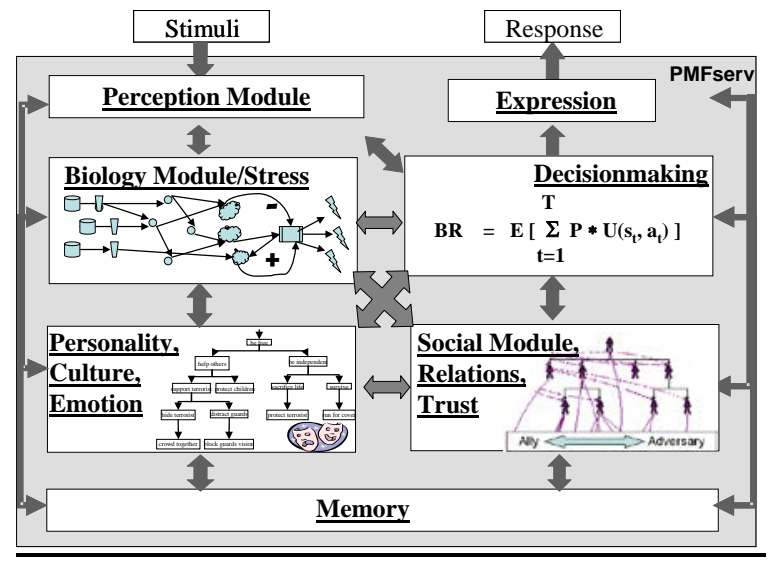

Further details of these PMFserv models are beyond the scope of this paper. Numerous surveys and syntheses of PMF models have been performed over the years and continue to be conducted. Interested readers should consult Silverman et al. (2006a, 2007). It is worth noting, however, that because the research goal is to study best-of-breed PMFs, we avoid committing to particular PMFs. Instead, the PMFs that are synthesized are workable defaults that our users can research and improve/edit on as time goes on. From the data and modeling perspective, the consequence of not committing to any single approach or theory is that we have to come up with ways to readily study and then assimilate alternative models that show added benefit for understanding our phenomena of interest. This means that any computer implementation we embrace must support plugin/plugout/override capabilities, and that specific PMFs as illustrated in Figure 2 should be testable and validatable against field data such as the data they were originally derived from.

Criterion 2, of course, takes micro-social science models out of their originally derived context and the synthesis exposes gaps and raises further questions about how valid is the collection. This is a topic for Section 2.4, but it raises the need for

Criterion 3: Can the Aqents Profile Realworld Individual Differences? - This is the concern that we must be able to represent multiple types of people (multiple perspectives). People are different and there is a need to be able to capture and represent those individual differences across physiologic makeup/stress, emotional arousals/value systems, decision style, ethnic norms/religious principles, social relations, and so on. Further, there is often the need to specify alternative hypotheses of the "behavior theory" (parameter profile) for a given 
individual or archetype and be willing to update and adapt that specification as new insights become available.

PMFserv has reached the level where it can realistically simulate ethno-political conflicts among regional leaders and their followers vying over control of contested resources and assets. Published validation studies for application in the South Asia, Mideast, Africa, and domestically are in Silverman et al 2006a, b, 2008. PMFserv is also in use by an intelligence agency to model diplomatic decisions of world leaders for which it has passed statistical correspondence tests showing it is significantly in agreement with their decision-making: see Silverman et al. (2007). Other applications use PMFserv to run both leader and follower agents and to use their microdecision making to study group dynamics and how macro-behaviors and new equilibria autonomously emerge. To support this profiling of different individuals we have invested in knowledge engineering and profiling technology. Silverman (2006b) overviews a methodology we utilize for profiling, while Bharathy (2006) is an INCOSE award-winning dissertation that substantially expands this methodology and provides support for alternative competing hypothesis of the behavior theory of either an individual or an archetype that one is attempting to model. This dissertation has been turned into a handbook and series of support tools, the most recent of which is a web-based interview that collects the needed information from subject matter experts who are unfamiliar with computational tools.

A final feature worth covering about PMFserv is that the agents are conversational. That is a player may interrogate them about the "behavior theory" or parameter settings of any of their tanks, goals, standards, preferences, social relations, group dynamics, decision making history, opinions about other agents and the actions they have done, opinions about FactionSim institutions and organizations (to be explained in the next section), how they feel about transgressions and transgressors, whether atonement is possible and how forgivable is the grievance, etc. In this way, the PMFserv agents can give qualitative explanations when they talk. PMFserv agents do not parse natural language queries, but instead expose a large list of things you can talk to them about. Also, in given applications (see Section 3), the PMFserv agents can air their concerns and ask the user to help them solve them. All these capabilities increase the transparency of the agents and help users to understand their perspectives and situations in a conversational way.

\section{2) Social Layer: Descriptive Modeling and Social Theory}

According to Bankes (2002), "agent based modeling is a revolutionary development for social science. However the reasons to expect this revolution lie more in the potential in this tool than through realized results". We are interested in utilizing agent technology, yet in a way that will help it live up to its potential. Armstrong (2004) studied the techniques for forecasting conflict vs. cooperation. He showed that statistical modeling, game theory, operations research, delphi, and most other traditional methods have an abysmal record -- they are no better than pure random chance. The techniques that do seem to work are knowledge-rich analogical reasoning (prior experience) and role playing games. Specifically, the techniques that work best are those that get the decisionmaker to think through the perspectives and to empathize with the affected parties. As Swedberg (2001) states, "If sociological game theory is not to end up as an artificial exercise, ..., it is absolutely essential that the beliefs, ideas and experiences of the actors themselves are moved onto center stage".

The methodology my lab has been pursuing for nearly a decade is inclusive of all types of knowledge and modeling - exoteric and esoteric, hard and soft, complex-emergent, and conflict- 
emancipatory - whatever works best for the situation being modeled. However, it has primarily focused on profiling what actual people do, on making the agents more and more realistic, and on synthesizing descriptions from multiple knowledge sources. At the same time, this is consistent with the warnings of Rittel \& Webber (1973), with the sweeping in enemies dictum of Experimentalists, with the pragmatism idea of multiple perspectives, and with the esoteric and qualitative modeling found in much of the social sciences. The centerpiece of an inquirer system needs to be the descriptive, not normative, approach.

Edmonds \& Moss (2004) argue that we need to move away from the concept of simplicity of models - the so-called Keep It Simple, Stupid (KISS) principle that is so often cited in the complexity, game theory/OR, and agent modeling fields. Given the richness of social domains, the need to model as much detail as possible, the vast amount of information and news on the web, and the power of current computers, they suggest a new mantra - Keep It Descriptive, Stupid (KIDS). KIDS seems particularly appropriate for social simulations and Singerian Inquiry agents. Edmonds and Moss are a little vague on what is descriptive, however, and that is open to research in this new paradigm.

In social science, this is more generally called the "social theory" of the situation: e.g, see Miles (2001). Anthropologists and ethnographers have well-established, labor-intensive methods for fleshing out such theories: (Kottack, 2005, Atkinson, 1983). The social constructivism movement, particularly in International Relations, also offers a number of approaches for understanding structure and agency and how they arose within a given nation-state or region of interest: e.g., see Wendt (1999) among many others. Systems thinkers have also developed tools and methods appropriate to extracting a systematic description of the state of affairs for a given region or organization: e.g., Ackoff (1981)'s mess formulation or Checkland's soft system methodology. From this literature, we can see the need for

Criterion 4: Does the model promote a descriptive social theory (agency, structure, time, space)? - The necessary elements of a social theory must encompass the structural and agency dimensions of a social system and their spatial and temporal distributions.

That is, any social system can be thought of as structure and agency distributed over space and time - these are the teleological parts or subsystems. Institutionalists in the social sciences tend to focus on the institutions and organizations affecting and shaping a society (health, education, law and order, regime structure and elections, religion, formal and informal businesses/economy, etc.). By contrast, agency covers the decision making, relationships, and teleologic purposefulness of individuals - alone and in groups, leaders and followers - those who may affect each other and/or (more slowly) the institutions and organizations around them. Historians agree that many conflicts are about who gets to be in control of the institutions and the resources and services they allocate. So this involves a spatial issue regarding access to and control and development of institutions and organizations over space (terrain) and time (history). The historic roots of ethno-political conflicts can be traced to grievances related to structural issues and/or past agent actions.

The layer we added atop PMFserv to satisfy this criterion is called FactionSim (Figure 4). This layer facilitates the codification of alternative theories of factional interaction and the evaluation of policy or design alternatives. FactionSim is a tool that allows conflict scenarios to be established in which the factional leader and follower agents all run autonomously; use their groups' assets, resources, and institutions; and freely employ their micro-decision making as the situation requires. Macro-behaviors emerge such as, but one example, followers either supporting their leader's decisions and/or rejecting their group’s leadership and replacing him 
(sometimes violently) -- or -- withdrawing membership and mobilizing to a new group. Leader agents often find it difficult to move to alignments and positions that are very far from the motivations of their memberships unless they can impose authoritarian restraints. This environment thus implements PMFserv within a game theoretic campaign framework.

Figure 4: Architecture of FactionSim including Design Experimentation Dashboard, and Tools to Foster Dialog and Specification of Social-Behavioral Models, Design Ideas, and Evaluation Metrics.

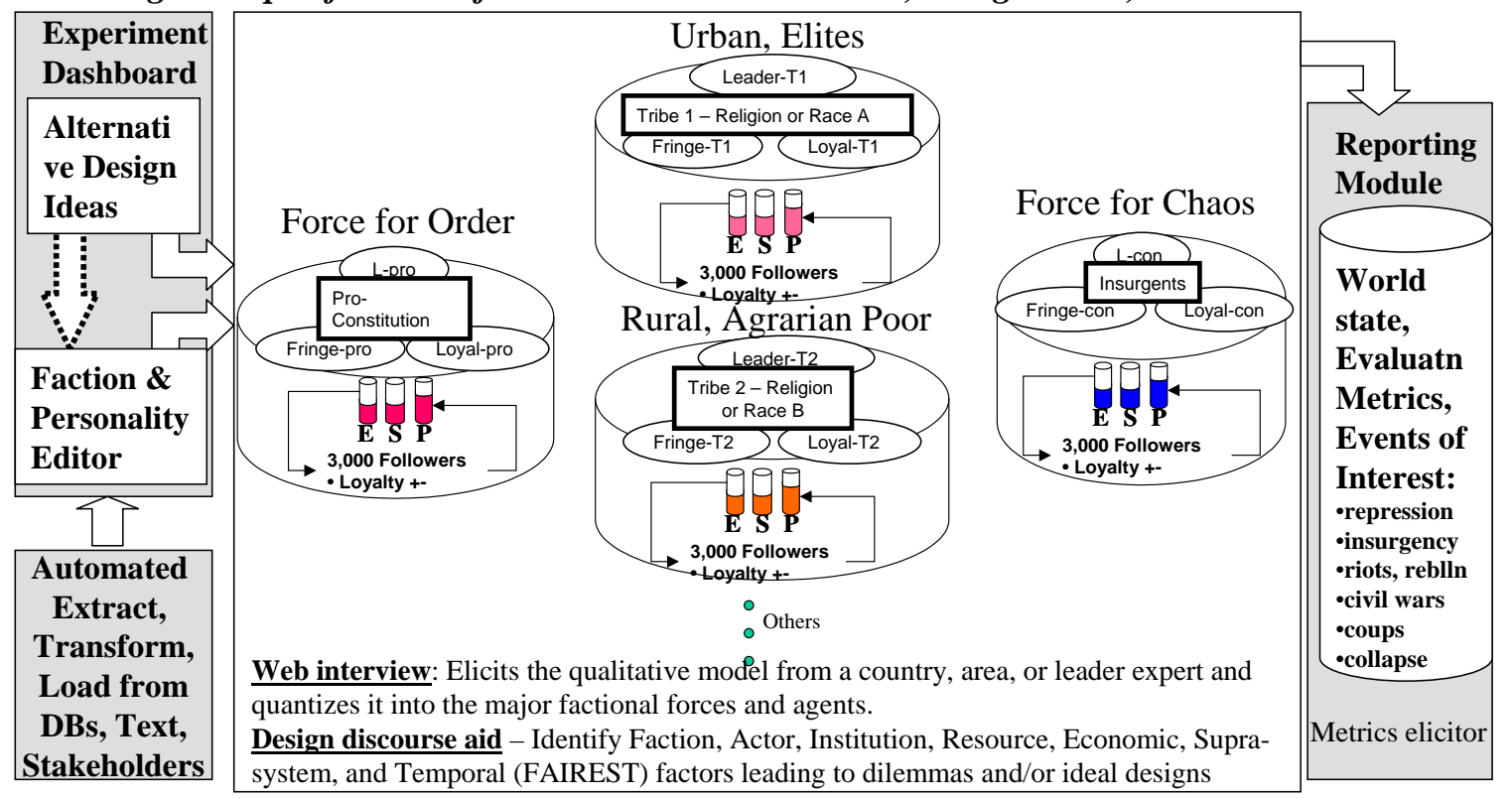

To set up a FactionSim game the stakeholders discuss and profile the items overviewed in this section. In effect this dialog causes them to create a system model and to think systemically about its current design and what may be an improved design, and how to measure improvements. These items may be edited at the start, but they also evolve as a game plays out leading to new questions needing to be answered about the social reality being modeled and measured. In addition there are many parameters that are automatically generated (e.g, the 22 emotions of each agent, relationship levels, models of each other, etc.). Profiling includes the following social theory parameters and models (a web interview is used by SMEs to initially fill in these parameters in about 12 hours time). This interview follows the acronym of FAIREST (faction-by-faction actors, institutions, resources, economics, supra-system, and timelines). We also use the FAIREST scheme to stimulate conversation about new idealized designs (and metrics) that seek to mitigate negative factors and promulgate positive ones. The list below is elicited for each major factional group in a region.

Factions of the region:

$\square \quad$ Philosophy, Sense of Superiority, Distrust, Perceived Injustices/Transgressions

$\square \quad$ Leadership, Membership, Other Roles

$\square \quad$ Relationship to other groups (ingroups, outgroups, alliances, atonements, etc.)

$\square \quad$ Barriers to exit and entry (saliences)

$\square \quad$ Institutional infrastructures owned/controlled by the group

$\square \quad$ Access to institutional benefits for the group members (Level Available to Group)

$\square \quad$ Fiscal, Monetary and Consumption Philosophy

Agents (Decision Making Individual Actors) that fill the roles (leaders, followers, ministers, etc): 
$\square \quad$ Value System/ GSP Tree: Hierarchically organized values such as short term goals, long term preferences and likes, and standards of behavior including sacred values and cultural norms,

$\square \quad$ Ethno-Linguistic-Religious-Economic/Professional Identities

$\square \quad$ Level of Education, Level of Health, Physiologic/Stress Levels

$\square \quad$ Level of Wealth, Savings Rate, Contribution Rate

$\square \quad$ Extent of Authority over each Group, Degree of Membership in Each Group

$\square \quad$ Personality and Cultural Factor sets (conformity, assertivity, humanitarianism, etc.)

Institutions available to Each Group: (Public Works, Protections, Health/Education, Elections, etc.)

$\square \quad$ Capital Investment, Capacity for Service, \# of Jobs

$\square \quad$ Effectiveness, Level of Service Output

$\square \quad$ Costs of Operation, Depreciation/Damage / Decay

$\square \quad$ Level of Corruption (indicates usage vs. misuse), Group Influence

Resources:

$\square \quad$ Group Level Resources such as Political, Economic and Security Strengths

$\square \quad$ Disparity, Resource levels, Assets Owned/Controlled

$\square \quad$ Power-Vulnerability Computations (Johns, 2006)

- $\quad$ Skirmish Model/Urban Lanchester Model (probability of kill)

Economy Model (Dual Sector - LRF Model)

- Formal Capital Economy (Solow Growth Model)

- Undeclared/Black Market

Supra-System

- $\quad$ Political Model (loyalty, membership, voting, mobilization, etc.)

- Info Propagation/Votes/Small World Theory

- $\quad$ External threats

Time Periods (how will the FAIRES items shift across near, mid, and long term under current conditions and with new designs. If the model runs do not produce satisfying answers, new questions arise and must be answered)

Note that in addition to leaders and followers of groups, FactionSim includes models of all the FAIREST factors - e.g., institutional agents (ministers are PMFserv agents) autonomously dispense services and resources via institutional infrastructures. Typical institutions include the economy (markets, jobs, banking), educational system, the health system, the judicial system, the police and security forces, the utilities/infrastructure (e.g., energy sector, the transportation system, and communication systems), as well as various institutions of a modern polity including an electoral commission that conducts elections and collects votes. These institutions and the institutional economy module are new additions this past year to the FactionSim and they are being extended for the purpose of building virtual countries and neighborhoods. FactionSim (as does PMFserv) also supports plug-in of more detailed models of these dimensions, though there does not seem to be a literature on this topic of corruptible institutions or of bottom-up economic models, especially in the developmental economics field. Still, the goal of this framework is to identify and synthesize best-of-breed third-party models so that a better capability evolves. What is not pre-determined are the parameter values or levels of the FAIREST models. That is what the interviews and dialogs are about.

Beyond this, it is important to state that while Criterion 4 suffices to minimally cover a social theory, we also need: 
Criterion 5: Does it foster collecting the differing perspectives of the social situation? - It is necessary for the social theory to also represent the perspectives of the diverse stakeholders of the social system.

Churchman discusses the "sweeping in" of multiple perspectives. This is far from simple. It often takes the form of collecting micro-views of micro-theories to begin with, those about different subsystems and/or individuals or organizations. These perspectives are collected from the stakeholders where possible, and from SMEs and other online resources. The esoteric knowledge of the PMFs and FAIREST models can serve as a driver of what information to collect. After a lot of these views are collected a macro-view of the socio-political-economic situation begins to emerge. The idea of an agent based model focuses and sharpens the representation of what is captured. It also can be run in simulation model and compared to real world events. If it deviates, then this may be a sign that not enough of the social and behavioral theory have been captured and described.

One oft-cited philosopher with credentials in this arena is Jurgen Habermas. Habermas (1987), and Giddens (1994) as well, suggest dialog and discourse ethics necessary to extract the multiple perspectives from potentially oppressed groups (women, the poor, minorities, etc.). The result is what Habernmas calls "critical social theory" -- one that is a correct theoretical representation of how things are with individual agency and social structure. Barton et al (2004) survey newer approaches of systems scientists trying to grapple with power dominance, and point to the community-driven change conferences of Emery, among others.

When it is not possible to collect the critical social theory directly from the mouths of the diverse groups and participants in a given social system, one alternative is to embellish that by using subject matter experts, social scientists who are country or area experts. Such individuals tend to study all the groups of a region, their writings, their history, their networks, and so on. They form a qualitative social theory of the situation as a mental model that may be extracted and quantized into a model such as described here. Using experts' models is feasible, but it is not without concerns such as Tetlock (2007) and Heuer (1999) present.

Criterion 3 talked about alternative hypotheses of the behavior theory of an individual or archetype, and in the same sense, the social theory may need to be revised as new insights are gleaned. Indeed as one spirals through micro- to macro-views of a region's socio-politicaleconomic situation, several parallel hypotheses may need to be maintained until enough evidence is obtained to reach a judgment that one or ther other prevails. There is much written on these points, and it often may appear that a realistic social theory cannot be created if the world is changing too rapidly (as under post-modernity assumptions) or if the design ideal cannot be fully defined or reached, given the constraints of local narratives. However, it seems that Layder (1998)'s “adaptive" criterion is reasonable and we adopt it here as

Criterion 6: Can the social theory be readily revised and adapted? -- A social theory should be informative and a 'best approximation' or model of reality, but it should be intrinsically capable of reformulating and adapting itself with the discovery of new data or insights into that data.

One of the techniques in FactionSim that support the agents being able to automatically reformulate their model of reality is that we encode the social theory outside the heads of the agents. Thus their behavior theory is independent of the social theory and need not be altered to update the social theory. This is accomplished as described in Cornwell et al. (2004) where in addition to managing agents, PMFserv also manages objects (representing both agents and nonagents, such as a car, location, a business, etc), including when and how they may be perceived 
and acted on by agents. PMFserv implements affordance theory, cognitions of the world are situated in the objects of the world, and maintained there, meaning that each object applies perception rules to determine how it should be perceived by each perceiving agent. Objects then reveal the actions (and the potential results of performing those actions) afforded to the agent. For example, an object representing a car might afford a driving action which can result in moving from one location to another. A business might afford running it, working there, purchasing goods, and/or attacking and damaging it. These object affordance markups permit the PMFserv agents to perceive and reason about the world around them. New objects or revised definitions can be readily added with no impact on the behavior theory of the agents, no need to revise their descriptions. In general, an ontology of a great many objects and content encyclopedias are being pre-encoded in its libraries so that scenario developers need not fill in the markups, but only need to link them to structures, areas, organizations, etc. of that region.

Abstract objects, such as plans, obligations, and speech acts, are represented in the same way as concrete objects. For example, we make use of this representational form to store historical grievances and new social transgressions as they occur in the simulation. Knight et al (2008) conducted a thorough survey synthesis of the relevant literature (Criteria 1 and 2) which we recap here to clarify this example. By "social transgression" we mean an offense an agent can commit against social rules. We utilize a simple, yet comprehensive taxonomy of the types of transgressions possible. All transgressions have a transgressor, a set of victims, and a set of effects. Effects are the direct effects of the offending action, not the emotional effects on observers. The latter are handled internally by the PMFserv agents. Beyond these basic properties, our transgression objects keep track of some relations with the transgressor, relations with observers, properties of the effects, and relations between the transgressor and observers. The transgression objects also keep track of atonement actions emanating from transgressors and their agents (e.g., compensation, apology, etc.) and forgiveness actions by the victims. A transgression may be forgivable or unforgivable. It seems that most people view most transgressions as, at least in principle, forgivable. However, some people may view some transgressions as unforgivable, at least until some condition occurs (such as repentance of the transgressor). Among forgivable transgressions, a transgression may be forgiven or unforgiven. This means that the observer in question may have forgiven the transgressor for the transgression. There are still many open issues on this topic - incomplete information, communication, collective responsibility, attribution of blame, apology sincereity, etc. But this is an example of a capability that encapsulates functionality so that knowledge revisions can be made to one part of the system (eg, who are the transgressors and who are the victims) without having to alter other parts of the system (e.g, behavior theory of the agents). This means that the agents can automatically revise their conception of the social situation as new information comes to light and is added to the markups, or as the agent world evolves and develops autonomously.

\section{3) Social System Design and Computational Experimentalism}

Science is a method of inquiry into what already exists and what insights may be discovered about it. But the purpose we turn to in this section is the design of the new, the creation of idealized worlds and institutions. This is not the process of finding and characterizing the problem space or prevailing societal situation. It is the process of scoping out a solution given one is dissatisfied with the current state of affairs. The method of inquiry of most utility here is design: eg, see Ackoff (1974), Banathy (1996), Checkland (1977). Design is a process of solution finding that relies on cross-disciplinary synthesis. Unlike the disciplines that scientists 
reductively examine, design must look for holisms with a constructive lens. This is not the operations research "social engineering" that was faulted in the early 1970s (Ackoff, 1974, Banathy, 1996). Design is the method suited for transforming existing socio-technical worlds into desired ones.

Design must be distinguished from forecasting, planning, or problem solving. Forecasting is involved with predicting how the future will turn out given some current state of affairs. Yet design is the process of changing that future, so the forecast is obsolete. Planning is figuring out the sequence of steps and resources needed to reach a goal or end state, but design is the process of coming up with what that end state should be in the first place. Planning should not begin until design is finished. Finally, problem solving involves focusing on and representing the problem. The more time spent on problem definition, the clearer the path for finding and testing solutions to that particular problem. Design does the opposite. It rapidly focuses one on idealizing and representing solutions that cut across many problems. Since social systems are open systems that operate in turbulent, ever-changing environments, problems are invariably symptomatic of interdependencies within these larger emergent wholes. The design approach responds continuously and systematically.

Several variants of design inquiry for social systems have been postulated and used. In these methods, one ideally collects all stakeholders together and they jointly design an ideal future. That self-design approach is a key to acceptance and sustainability. If the stakeholders' preferences are all voiced, and they can agree on a shared vision, there is no better method. Often though it is difficult to do this for a variety of reasons. In competitive, conflictual, or coercive situations, this process depends on convincing the stakeholders that it is in their respective interests. That is not always possible, and in practice certain worldviews get adopted.

Ackoff (1974) and Herman Wrice used this approach to create a process they applied to selfdevelopment and transformation (not gentrification) in impoverished urban areas. Here, "true" social leaders (those who really get things done) must be discovered and nurtured/developed so that they can be empowered to lead the discourse about what is a shared idealized design or future and to then make and sustain the needed changes. While the first instantiation of this deviated a bit from interactive planning, it illustrated idealized design. It has lead to a grass roots movement known as Turn Around (your town) or "Turn Around America - The Wrice Process". This has largely been applied to chasing drug dealers, gangs, and prostitutes from a community. This is an urban recovery process that has since been applied across over 400 communities straddling 20 states in the USA and has been exported to other cultures as well.

Similarly, in conflict zones, Eizenstat et al (2005), Kilcullen (2004), Patraeus \& Nagl (2007), and Dziedzic \& Perito (2008) among many others, describe the need to begin with security and protections and the further need to coopt the agenda from the opponents advocating chaos and anarchy. Only then is ethical and meaningful discourse possible with the aim of moving toward reconstruction, and self-sustaining institutions that assure widespread freedoms. Like Ackoff and Wrice, they also explore the need to help train/develop the clients (structural services and freedoms/agency) to empower them to lead and sustain an emancipative movement.

Many others have contributed to ideas and methods to helping the design process in conflictual settings. Here are but three illustrative examples, ones we have already built or partially built into the agents described here. Eidelson and Eidelson (1999) offer an instrument for profiling the beliefs of individuals about the groups they belong to and that they interact with. This helps to start the dialog about their differences. Howard (1994) examined how to convert game theory into soft game theory that better accommodates people's emotions and diverse 
preferences and payoff functions. Ultimately, he evolved this into drama theory which involves writing each other's plight and sharing the stories in the effort to foster empathy and a cooperative stance. We have observed other conflict graphing tools that also support eliciting the positions and dilemmas of the current factions and working toward solutions: e.g., Hipel (2007), among others.

Whoever participates in the design discourse must imagine the "idealized design" or idealized future state of the system. That is, they imagine the world is already at that state (end). Many techniques can help a group to visualize and re-visualize this ideal until they arrive at a shared vision of the world. We tend to make use of a fishbone diagram of the world state with the ribs corresponding to the seven FAIREST dimensions. Profiling the actual social system helps one to describe the negative and positive factors affecting each of these "ribs" and leading to the current social dilemma. Likewise a similar diagram can foster discourse about how to remove the negative factors and amplify the positive ones so that order can be restored and the system can become self-sustaining. Running these designs in FactionSim can then help one to explore the possibilities and confirm their effectivity and robustness.

The teleological agents and social organizations of the meso-scale architecture are wellsuited as a modeling method for capturing people's ideals, preference or payoff functions, group identity feelings, and even absolutist tendencies. As mentioned much of this is stored in the GSP trees of an agent's value system, though some of it is captured in their group roles and relations and in grievance objects and encyclopedias. In the GSPs, the preferences are indeed the agents' ideal states of the world. The standards indicate what methods and actions they condone to reach those states. These agent models are intended to "sweep in" and hold the representations of all the differing perspectives, adversarial views, concerns of the alienated and disenfranchised, etc. Once set up, these type of models can help users to examine possibilities of alternative futures. That is we can use them to systematically explore shifts in the social design or state of the world, and how robust a given state's situation is or how sensitive and fragile is its situation.

To enable that type of analysis, one must first collect the current state of the social system and dilemmas it encompasses. This is what social scientists can be good at. Ethnographers generally try to identify the forces at play and the sources of unhappiness so one may then turn toward questions of stabilization and reconstruction -- work toward improvements. There are numerous challenges to this objective, however. We already addressed and dispensed with the post-modernist defeatists and will not repeat that here. Rather, here we take the view of technologists and ask whether the world scene can be automatically generated. Elsewhere, we explore the pros and cons of automated event coding and scraping from databases, news feeds, and websites. This is an attractive proposition, but at present it does not yet seem to work for the types of parameters of interest here. There is a lot of funding for improving this situation and it may yet change, but for now we have adopted a web-based interview that qualitatively collects all of the parameters of our model collection from subject matter experts. This raises:

Criterion 7: Will it Foster Rapid Scenario and Agent Generation? - The creation of a virtual design inquiry world should itself be usable, engaging, and productive.

The qualitative collection of scenario descriptions and profiles of the socio-political climate, groups, assets, and personalities is itself no small task to design effectively. We all have familiarity with the divergent opinions of political pundits and the importance of using multiple sources of competing evidence and of analyzing counterfactuals. Heuer (1999) and Tetlock (2005) make other useful points about the difficulties of expert political judgment. Bharathy (2006) provides an examination of a number of tools that we make use of for evidence 
collection, competing evidence and hypothesis analysis, comparative judgments, and so on. The end result, however, is a web interview process that permits experts to assemble their own models of the situation. Since the interview is in qualitative form (e.g., Likert scales), the SMEs do not need to be computer scientists to author social system models. Current experience is that these forms and the discussion about their parameterization becomes an engaging and purposeful activity for experts alone and in meetings. Further, one would ideally prefer this to occur not in a back room, but to be filled in by the stakeholders themselves for a given social system.

Once they complete the profiling questionnaires and describe the current social system, the result is a populated computational agent world. These simulation spaces are intractably large, but they do represent topological surfaces that one ultimately can search with various sampling protocols (e.g, Latin hypercube, statistical, OR/optimization, GAs, and AI/heuristical). The slopes of those hilly surfaces should be important indicators to think about. Likewise, one can contemplate standing at an ideal omnicompetent future (perhaps to be defined for each area or multi-factional set of groups somewhat uniquely) on this topology and using the tools to help examine how to remove all the obstacles and constrain all the adversaries to reaching that future ideal (altitude). This of course introduces the idea of design flaw detection and it must satisfy:

Criteria 8: Does the Environment Support Computational Experiments? - Experimentation dashboards and sensitivity analysis editors should support representation of alternative hypotheses of the diverse stakeholders of a region and exploratory studies of how they will likely react in the current situation and to alternative futures (designs).

This modeling approach requires the inquirer organization to collect data to continually measure how well the models work, and to further improve their performance. There are, after all, no perfect modeling techniques. The effort to build and operate models is intended to help an organization to think more quantitatively and clearly. By improving the models continually, one exposes the gaps in what science knows and doesn't know, and by that begins to improve the science and practice in this field.

A design inquirer must also be anchored in the elicitation of measures and metrics of performance that fall at the system level. Such measures are substantively and conceptually different from traditional human performance measurement, which emphasizes measurement of efficiency and error rate on delimited and stable tasks in a "one person-one machine" context. For network science, measurement must scale up to team performance, organizational performance, and social system stability. Cohen (2006) provides a number of relevant guidelines to elicit the metrics of a social system's performance in such a way that they do not become politicized and abused. There are many unanswered questions about whose metrics to use and how to calibrate them for a given social system and what cutoff thresholds to apply (e.g, how many deaths per year are in a civil war? Do 10,000 murders/year in the USA imply the same thing in another land? etc.). Moreover, it may be critical that measures of shared under-standing, situation awareness, and protections and freedoms for individuals be observable non-invasively.

Criterion 9: Does the Agent World Permit One to Choose/Show Metrics of Stability and Reconstruction and Does it Support Transparency and Drill Down? - A descriptive agent world should come with tools eliciting the system level metrics and for drilling into the measures of performance to see what emerged, what events occurred, and who did what to whom and why.

A descriptive, virtual world rapidly outpaces a user's ability to see what is cause and effect. There are so many actors, groups, causes, and emergent effects that it is difficult to trace through them all. Measures of performance of the virtual world will inevitably need to be hierarchical 
showing high level summary metrics that the users deem worth tracking (eg., equilibrium shifts, changes of governance, rebellions, systematic discrimination, etc.) and computed from combining different summary indicators and trends. These indicators in turn will summarize the events that transpired and transactions that occurred in the agent interactions. In some regards, there are some well known metrics and indicators to follow in any given region, while in other regards this is an open research question and a design inquirer will tend to research and evolve its own set: e.g., see Cohen (2006). To respond to this, a meso-scale simulator must add a flexible backend editor to permit users to author a hierarchy of metrics and a database to automatically collect and display them after each run of the system. We have experimented with this and are looking at various frameworks to help out (eg., see Cohen (2006), Anon (2008)).

The backend viewers should permit one to drilldown from high level system metrics to intermediate indicators to actual events that are being counted. Once a given agent is noticed to have made a significant decision or action choice, PMFserv agent worlds provide new opportunities - both to include novel indicators, and to interrogate the simulated actors directly. Since the agents are conversational, they can explain how they feel about the current state of the world, about their own condition, about the groups in the region and their leaders' actions, and why they took various actions and how they felt about doing so. Finally, one can trace these actions back to starting conditions and inputs from the web interviews. No one can eliminate hyper-confluence in large agent simulations, however, capabilities such as these are essential to help the analyst get a handle on isolating the likely causal sources of a given instability or event.

Taking all the trouble to assemble a design inquiry system to emulate a social system and its dilemmas is a large effort as the reader can see. One continually adds to what one knows about that social system and how it is evolving and adapting. This large corpus of insights about the social system can offer a dual use purpose to permit individuals to rehearse their operations before trying them out in the real world. This differs from computational experimentation and Monte Carlo techniques in the sense that it becomes a role playing and even an immersive gameworld. One can benefit enormously from playing the parts of some of the stakeholders in order to gain insights about what they are going through. Armstrong (2004) indicates that role playing games is the most effective technique for forecasting. Further, if one can explore in a simulated or immersive world and discover insights, there is ample evidence that this is a highly effective way for many people to learn, retain, and indeed transfer knowledge into practice. For these reasons, it is useful to add tools and models that facilitate the architecture being able to satisfy:

Criterion 10: Does the Toolset Afford Socio-Cultural Training and Rehearsal? -Descriptive, conversational agents are a rich basis for training about and rehearsal with the diverse individuals, groups, and institutions of a social system.

\section{4) Case Studies of the Meso-Scale Architecture}

In this section we look at two spin-off applications of the meso-scale architecture and methodology. One is for state level modeling and the other is for tactical regions. There are separate papers on each of these applications. The point here is to use them as illustrations of how the meso-scale socio-cognitive framework can support social system design inquiries.

\section{1) State Modeling}

Weak and failed states has been identified as one of the major risks to US and global security (Krasner \& Pascal, 2005) and it is a priority of US foreign policy to understand their 
stabilization and reconstruction (Eizenstat et al, 2005). With such concerns in mind, in 2008 we used the meso-scale framework of the previous section along with a country map viewer and made this into a generic application for authoring country models that we call CountrySim. CountrySim's web interview (criterion 7) elicits qualitative state and sub-state models from the heads of country and area experts. It quantizes these experts' models using the full set of FactionSim capabilities (criteria $1-6$ ). The Thailand model is illustrated in Figure 5. The left side shows that hierarchies of PMFserv agents play rival leaders and followers within each faction (and it allows many factions). Also, agents can play the institutional ministries that allocate services and resources to the factions (or not).

We have applied the framework to model 10 representative countries across Asia as part of a DOD challenge grant (e.g., China, India, Russia, Bangladesh, Sri Lanka, Thailand, N. Korea, etc.). Specifically, fourteen of the best country experts in the USA were hired to use the web-enabled frontend to express their country model (they profiled all factions, institutions, leaders, follower archetypes), typically in about 12 hours time per country.

\section{Figure 5 - Overview of How the PMFserv-FactionSim Capability Serves as a Generator of} "Design Inquirer" Tools for Systems Social Science Training and Analysis

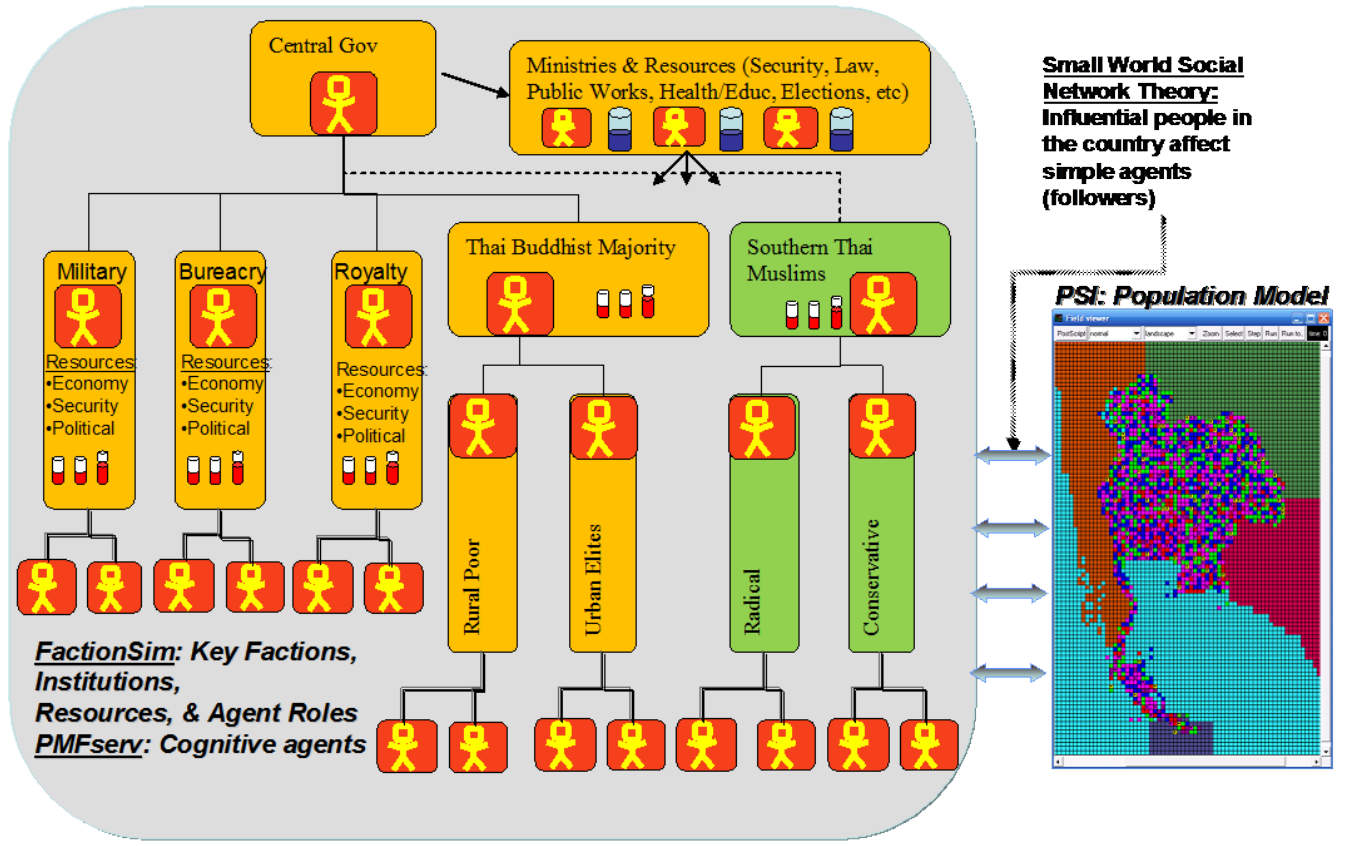

As Figure 5 shows, there also is a bridge to the PSI population substrate through which the cognitively-detailed PMFserv agents pass on their actions and decisions that effect the 10,000s of simple agents in the landscape. This PSI landscape is the topic of several published papers (eg, Lustick, 2004), and we will describe it only from the viewpoint of the services it provides to CountrySim. Specifically, PSI organizes the simple agents in a spatial distribution similar to how identities and factions are geographically oriented in the actual country. This provides detail about regime extent and reach, and about message propagation delays that FactionSim alone omits. The FactionSim and PSI landscape agents thus are bridged together and a two-way interaction ensues in which FactionSim leaders, ministers and influential follower archetypes tend to make decisions that affect the landscape agents. In the socio-political context of CountrySim, the landscape then propagates the impacts and returns simple agent statistics that 
FactionSim uses to update faction resources and memberships, count votes for elections, and in part determine some of the well-being and instability indicators used in our overall summary metric forecasts and computations.

CountrySim as just described offers a capability that is unique for analysts in at least three dimensions. It does of course support the exploration of possible futures and sensitivity experiments (criterion 8), however, that alone is not unique to our approach. In terms of novelty, (1) it elicits the qualitative models of Subject Matter Experts (SMEs) of a given nation and permits them to run a quantized version of their model. These SME models tend to differ from traditional statistical (or even AI models) models and often incorporate insights into the personality and underlying motivations of the leaders involved, insights about the cultural traits and ethno-political group cleavages, and local knowledge about the history of grievances and transgressions at play. Eliciting this permit us to better understand each SME's model (s), observe its performance, track its forecasts, and help to improve it over time. (2) We offer a uniquely transparent drilldown capability (criterion 9) where one can trace potential causalities by working backwards from summary outcome EOIs (Events of Interest) to indicators and events that are summed up in those indicators. Further, one can find the agents that precipitated those events and query them through a dialog engine to inspect their rationale and motivations that lead them to the action choices they made. This is very helpful to analysts trying to diagnose potential causes and find ways that might better influence outcomes. (3) Finally, as per criteria 1 -6 , we have been integrating best-of-breed theories and practices from the social and behavioral sciences and engineering them into the simulator components - in fact components are built exclusively by synthesizing social science theories. The SME mental models are elicited as parameterizations of these best practice scientific theories/models. As such, we provide a pathway for studying the underlying social sciences including their strengths, gaps, and needs for further research.

The model controller and Monte Carlo dashboard permit studies to be run, while the back end supports measuring and inspecting the impact of policy interventions. Results to date for four countries are published and reveal significant correlations of the simulated with real world agents in historical recreation scenarios (Silverman et al, 2010). Further tests and experiments are ongoing.

\section{2) RegionSims and the NonKin Family of Tools}

At the vanguard of any effort to stabilize and reconstruct a state or region, is the forces that first must help to assure the security. The vanguard is often US Marines and soldiers sent in to begin the early stages. As per Criterion 10, the intent is for model users to be able to interact effectively in foreign cultures and ethno-political settings. This means they need to learn and rehearse how their actions and operations influence stabilization and reconstruction outcomes.

NonKin is the name of our generator intended to bring FactionSim into focus for human terrain in tactical regions (as CountrySim does for states). Specifically, NonKin is a scenario generator meant for use to implement villages, towns, and city neighborhoods, including connectivity of these areas to higher level institutions and assets. Factions and institutions/organizations and roles are defined with the help of FactionSim, while agents are driven by the PMFserv engine. The more one learns about the population, factions, institutions, infrastructure (the FAIREST items), the more faithfully the agent world recreates what is driving the actors in the real world. 
NonKin also is a SimCity genre of game engine. It is a role playing game generator that permits users to participate in the region and interact with its participants. The agents, institutions, factions, militias, and so on carry out daily life and various economic, political, familial, and security activities.

Figure 6 - Applying FactionSim at the Tactical Level with the NonKin Generator: Hamariyah Village

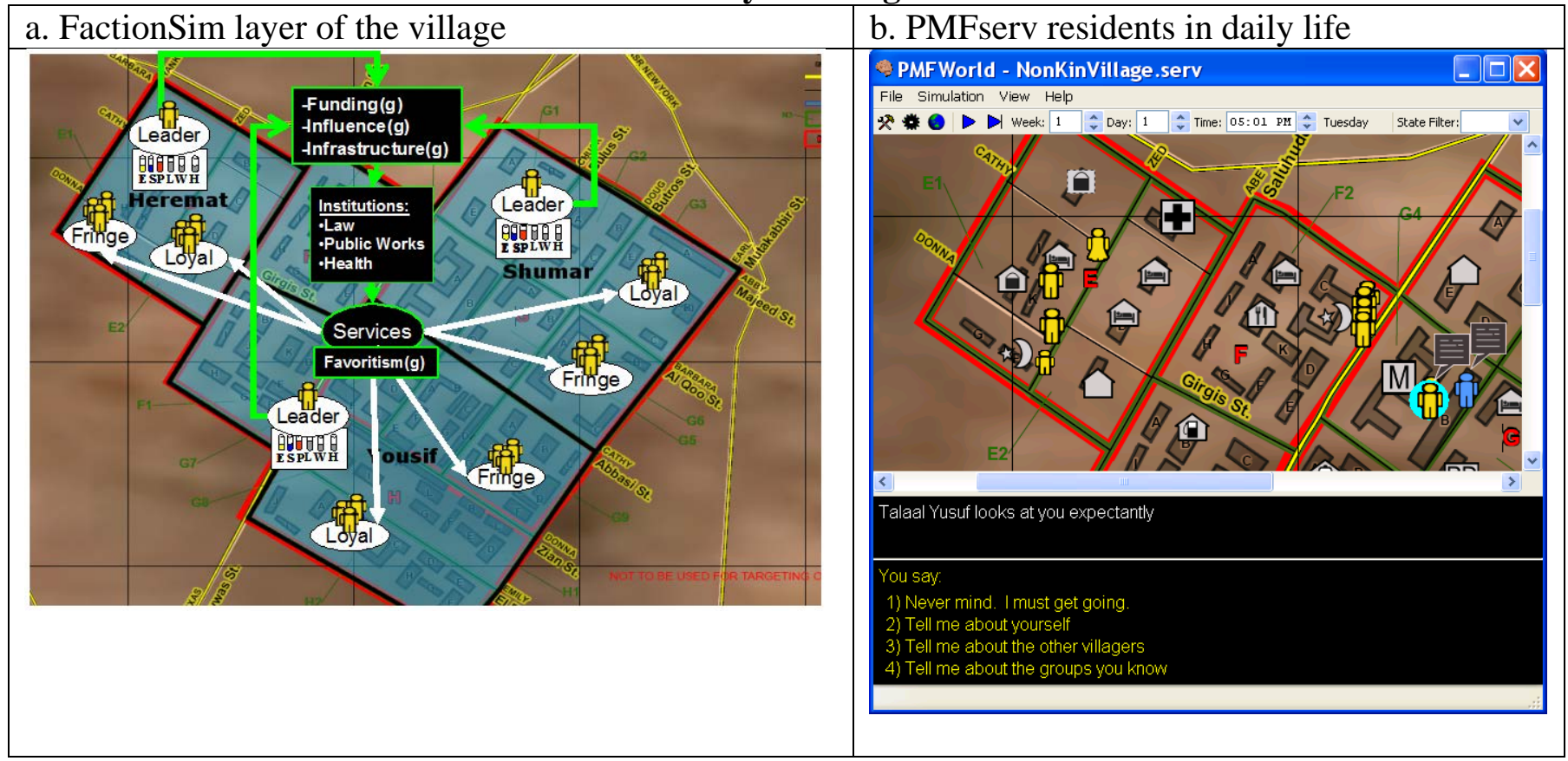

The first version of NonKin was prototyped with the help of the Fall 2007 undergraduate class in agent based modeling \& simulation (ESE 308), who worked with the assistance of two doctoral students (Ben Nye, Deepthi Chandrasekaran), an Arabic culture expert (Ransom Weaver), and lab programmers to author the roles, markups, utterance catalogs, and so on for a small Iraqi village occupied by different factions and individuals. They tested some of the scenario authoring tools and helped to identify ideas for improving them. The class also designed their agents and deployed them into the village.

Shown in Figure 6 is the next scenario currently being implemented. This is the hypothetical town of Hamariyah occupied by 200 individuals. The USMC folks from 29 Palms generated Hamariyah and descriptions of the town history, its 200 residents, 3 tribal groups, families, jobs, institutions, inter-factional grievances, and so on. This is a paper-based description, though some of it was provided in csv files that we recast into spreadsheet workbooks that were then read by the PMFserv model constructor. It is a plan for a new town of human role players that they might deploy in 29 Palms. The high level goals of NonKin include using this scenario to illustrate:

- Easy to use scenario generator -- profile actual personalities, cultures, group norms, historical grievances, institutions, infrastructure, etc. (based on turning on/off toggles from libraries of reusable agents, organizations, and other types of objects)

- Easy to use training content generator that offers a number of default training tasks, tactics, and procedures. Provide multiple cases and different situations comparable to a Campbellian 
hero's journey of uncovering the current dilemmas and initiating the FAIREST designs that can be taken over and managed by simulated locals for a self-sustaining peace.

- Commit mistakes and errors in this simulated world so you don't need to commit them in the real world that it simulates.

- Receive missions, during-play coaching, and after action reviews from PMFserv agents.

- Support multi-player capabilities for sharing understanding of the social system, holding discourse about FAIREST redesigns, and joint deliberation about actions and their effects.

Many of these features are still under development and as of this writing we are about halfway through a 3 year research grant to flesh out some of its features. We also just received a second grant to work with a 3-D modeling firm to use NonKin to drive agents in an immersive first person shooter game engine.

\section{4) Conclusions and the Way Forward}

Post-industrial era technology is of unprecedented power and holds the potential for world threatening impacts on climate, security, health, and economic vitality. Many countries are still developing economically and socio-politically from agrarian to industrial societies, often governed by authoritarian regimes or partial democracies. The socio-technical dilemmas arising from these sources, whether by design or inadvertently, have global reach. In fact, even postindustrial era economies with enlightened democracies have trouble harnessing and controlling technological advance and the management of the planet for the betterment of all. The burden for redressing socio-technical dilemmas rests on the current generation to advance the designs of our institutions and infrastructure and the scientific understanding of our social systems so that the common interest of current and future generations is preserved.

This paper overviews a research program on extending the design inquiry approach to learning about and consciously improving social systems, and socio-technical systems. Section 1 explored the problem that social systems are so complex and rapidly changing, that many people are giving up on trying to understand them, on inquiry into how and why they function as they do. The purposefulness of each of a social system's parts is often thought to be impenetrable. We thus see the warnings of the end of science and the end of theory, with the large -omics, Google type search, and black box models serving as a substitute that can show trends and find answers without the need to understand causality. Social science is inherently fragmented into subdisciplines, positivism is passé, and reductive inquiry seems unable to answer the large social system questions of our era. Synthetic thinking and the systems and design approaches are well suited to this endeavor, though without being informed by the findings of the social sciences, they are unable alone to account for the many perspectives found in a social system's stakeholders.

Despite differences between inquiry under science vs. systems thinking, Section 2 asserted a positive complementarity relationship and explored ways we are strengthening that linkage. Systems approaches always use the findings gained from the social sciences (and professions or experts) when attempting to understand the current system as well as in fostering new designs. In turn, social scientists benefit from the results of syntheses and new system designs. This paper presented an agent based framework that uses rich descriptive modeling and that synthesizes best-of-breed social and behavioral theories. Ten criteria were outlined that guide the students and researchers in my lab - three on behavior modeling, three on social system modeling, and four on guidelines for using the framework for analysis and training. These are answerable 
criteria, but answering them requires a disciplined response, particularly as one realizes that they must be continually re-answered. Section 3 then presented three applications that are making use of this socio-cognitive agent framework to help create design inquiry approaches for international crises, state and sub-state societies, and local regions and neighborhoods. These are examples of systems social science toolsets and frameworks.

This paper has asserted that the synthetic approach or systems engineering of inquirer organizational systems and (agent-based and other) modeling and simulation combined with best-of-breed reductive social science theories holds the keys to a new path for social science what may be referred to as "systems social science (SSS)." Social experiments are not possible in the real world, so many social scientists tend to use similar cases throughout history as a substitute. The agent society approach is widely cited as a revolutionary new paradigm that permits directly experimenting on a model of the social system of interest. But much of that claim is tied to the notion of illustrating how simple agents and rules lead to emergent phenomena. Beyond that this paper has explored three added shifts. First, is the addition of rich descriptive material (exoteric and esoteric). From a social constructivist perspective, if the agent approach gets a plausible result (historical recreation, possibility space of futures that indicate the actual outcome, etc.), then this comes with an instant drill down to the causal explanations. This is no longer a black box approach based on correlations alone. Nor is it the simple agent approach. The open box, socio-cognitive, bottom up descriptions entail the "social theory" of what is going on. The richer and more accurate the descriptions, the more likely that design transformations possibilities can be meaningfully studied and experimented with. Second, when social scientists agree to collaborate under this paradigm they initially tend to pursue their traditional reductive PMF research and experiments. However, they are then shown the holes and gaps in the agent models that the implementation of their findings lead to. This near-immediate feedback causes them to re-orient their research agenda for the next round of empirical research. The result is expansionism (of their inquiry) and synthesis with other theories. Finally, when social science professionals (e.g., country and area experts) participate, their qualitative mental models are elicited and quantized by the web interview. This confronts them with extrapolations of their models into possible outcomes and allows them to explore causality and mechanism of those effects. Often the experts find they want to refine and embellish their models, especially when they discover omissions and inconsistencies that render the models incapable of recreating historical scenarios or of projecting into the near term in ways that are satisfying to the experts. For all these reasons the SSS approach may be seen as a shift to new methodology and toolsets.

Newness does not imply maturity. Almost every direction we turn to under this systems social science paradigm is fraught with unknowns. Each new situation is unique, and a new "social theory" or systems analysis of what is going on must be assembled, often to be followed by stakeholders' self-designed transformations. The inquirer architecture aims at doing this and gives high level principles and criteria, but this is an emerging science. We don't fully know how to collect the knowledge, how to model it, what mechanisms are at play in the teleologic parts and what helps/hurts them, how to measure progress in the real world, and so on. Each new conflict/coercive setting can be an experiment in synthesizing what social science knows and testing it in simulated socio-technical systems. If we instrument the real situations, collect the needed data, and share and study it/compare it to our simulated worlds, science will not die. Science will evolve into a careful consideration of alternative hypotheses that help to explain and continue the evolution and development of improved socio-technical systems, a topic that is poorly understood at present. 
My claim is that a new paradigm has emerged, and none too soon. In fact the claim could be interpreted as any of the following possibilities. Which is correct? I leave that up to the reader.

- SSS is a revolutionary new paradigm. It goes beyond meta-analyses and simple applications of General Systems Theory into a shift of social science from theoretic reductionism to pragmatic synthesism and descriptive KIDS modeling inside humanistic- and ethicallyguided inquirer organizations.

- SSS is just another camp, not a revolutionary new paradigm. It deserves to be studied alongside the other disciplines in the social sciences. With the advent of the computer, the web, proliferating newsfeeds, realtime geographic information and databases, new statistical and agent-based methods, and the facility of young researchers with all these techniques, it is earning at least a token seat on most social science faculties.

- SSS is a hand-maiden -- just a well-reasoned set of protocols for carrying out computational research in the social sciences. This is no different than the computational science protocols in any field - ie, theory construction, model parameterization, validation, experimental testing and simulations, model refinement, etc. A weakness of this argument though is that computational science has altered the nature of each science it has touched to date - physics, chemistry, and biology. It seems inevitable to do the same eventually to the social sciences.

\section{Acknowledgements}

I appreciate the many discussions with Russ Ackoff, Iraj Zandi, Johnnie Pourdehnad, and the doctoral students and postdocs in my lab. Thanks also go to my lab's unsung heroes, current programmers such as K.Knight, M. Poe, M. Roddy, N. Weyer, and those of the past. Also to many unnamed students who assisted with these projects. I am grateful to a number of public and private sector sponsors as well: AFOSR, Anhueser-Busch, Army-UO FACT, DoD, DMSO, GM Corp, HSCB Program, IMC Inc., Lockheed Martin, ONR-HPTE, Stata Corp, USG, and USMC (apologies if I have left some out). Finally, the author alone is responsible for any opinions, unsubstantiated claims, or errors made in this manuscript.

\section{$\underline{\text { References }}$}

[1] R.L. Ackoff, (1974), Redesigning the future. New York: John Wiley \& Sons.

[2] R.L. Ackoff, (1981), Creating the corporate future. New York: John Wiley.

[3] R.L. Ackoff, (2008), Interview with the author, August.

[4] R.L. Ackoff, F.E. Emery, 2006. On purposeful systems. New Brunswick: Aldine Transaction.

[5] Anon (2008), Measuring progress in Conflict Environments (MPICE): Metrics Framework for Assessing Conflict Transformation and Stabilization, Washington DC: US Inst. of Peace.

[6] T.G. Andersen, T. Bollerslev, F.X. Diebold, and P.D. Labys, 2003. Modeling and

Forecasting Realized Volatility. Econometrica - Journal of the Econometric Society

71 (2): $579-625$.

[7] C. Anderson, 2008. The end of theory. Wired Magazine, July.

[8] J. S. Armstrong, 2002. Assessing game theory, role playing and unaided judgment.

International Journal of Forecasting 18: 345-352.

[9] P.A. Atkinson, A. Coffey, S. Delamont, J. Lofland, and L. Lofland, eds. 1983.

Handbook of ethnography. Chicago: University of Chicago Press. The first printing is 2001 
Intelligent Decision Technologies Journal (v.4, n.1, 2010, pp. 51-74)

[10] S. Atran, R. Axelrod, R. Davis, 2007. Social Science: Sacred barriers to conflict resolution. Science AAAS. 317 (5841): 1039-1040.

[11] R. Axelrod, 1997. Advancing the art of simulation in the social sciences. In Simulating Social Phenomena, eds. Rosario Conte, Rainer Hegselmann and Pietro Terna, 21 - 40. Berlin: Spring.

[12] R. Axtell, 1999. Why agents? On the varied motivations for agent computing in the social sciences. Agent Simulation: Applications, Models, and Tools.

[13] B.H. Banathy, 1996. Designing social systems in a changing world (contemporary systems thinking). New York: Plenum.

[14] S.C. Bankes, 2002. Agent-based modeling: A revolution? PNAS 99 (3): 7199-7200.

[15] J. Barton, M. Emery, R.L. Flood, J.W. Selsky, E. Wolstenholme, (2004). A maturing of systems thinking? Evidence from three perspectives, Systemic Practice and Action Research, 17 (2004), 3-36.

[16] G.K. Bharathy, 2006. Agent Based Human Behavior Modeling: A Knowledge Engineering Based Systems Methodology for Integrating of Social Science Frameworks for Modeling Agents with Cognition, Personality \& Culture. PhD diss., University of Pennsylvania.

[17] Black, Fischer; M. Scholes 1973. The Pricing of Options and Corporate Liabilities, Journal of Political Economy 81 (3): 637-654.

[18] G.A. Britton, H. McCallion, 1994. An overview of the Singer/Churchman/Ackoff school of thought. Systemic Practice and Action Research, 7, (5): 487-521.

[19] P.B. Checkland, 1981. Systems thinking, systems practice. New York: John Wiley \& Sons [20] C.W. Churchman, 1972. The design of inquiring systems: Basic concepts of systems and organizations. Basic Books: New York.

[21] C. Cioffi-Revilla, S. O'Brien, 2007. Computational Analysis in US Foreign and Defense Policy. Paper presented at the first international conference on Computational Cultural Dynamics, August 27 - 28, College Park, University of Maryland.

[22] C. Cohen, (2006). “Measuring Progress in Stabilization and Reconstruction,” United States Institute of Peace Report on Stabilization and Reconstruction, Series 1.

[23] J. Courtney, J. Haynes, and D. Paradice, 2005. Inquiring organizations: Moving from knowledge management to wisdom. Hersey, PA: Idea Group Publishing.

[24] J. F. Courtney, 2001. Decision making and knowledge management in inquiring organizations: Toward a new decision-making paradigm for DSS. Decision Support Systems 31 (1): 17-38.

[25] J.B. Cornwell, K. O'Brien, B.G. Silverman, and J.A. Toth, 2003 Affordance theory for improving the rapid generation, composability, and reusability of synthetic agents and objects.

Paper presented at the 12th Conf on Computer-Generated Forces and Behavior Representation, SISO.

[26] M. Dziedzic, R.M. Perito, (2008), Haiti: Confronting the Gangs of Port-au-Prince, Washington DC: USIP.

[27] B. Edmonds, and S. Moss, 2005 From KISS to KIDS - an 'anti-simplistic' modeling approach. In P. Davidsson et al. (Eds.): Multi Agent Based Simulation 2004. Springer, Lecture Notes in Artificial Intelligence, 3415:130-144.

[28] R.J. Eidelson, and J.I. Eidelson, 2003. Dangerous ideas: Five beliefs that propel groups toward conflict. American Psychologist, 58(3): 182-192.

[29] S. E. Eizenstat, J.E. Porter, J.M. Weinstein, Rebuilding weak states, Foreign Affairs 84 (2005) 134-146. 
[30] D.L. Epstein, et al. 2006. Democratic transitions. American Journal of Political Science: 50 (3): $551-569$.

[31] A. Giddens, 1991. Modernity and self-identity: Self and society in the late modern age. Cambridge: Polity Press.

[32] J. Habermas, (1987). The theory of communicative action, vol. 2: The critique of functionalist reason, Cambridge: Polity Press

[33] D. Hall, and Y. Guo, 2005. "Supporting the complexity of inquiring organizations: an agent approach”, Ch. VI, in Courtney, J., Haynes, J., Paradice, D.B, Ed. Inquiring organizations: Moving from knowledge management to wisdom. Hersey, PA: Idea Group Publishing. [34] M. Herrann, 1999. Assessing leadership style. Hilliard, OH: Social Science Automation, Inc.

[35] R.J. Heuer, Jr., 1999. Psychology of intelligence analysis. Washington, DC: Center for the Study of Intelligence, Central Intelligence Agency.

[36] K.W. Kipel, Competition and cooperation in societal and technology systems of systems. Keynote address: 2007 IEEE International Conference on Systems, Man, and Cybernetics:

Smart Cooperative Systems and Cybernetics Advancing Knowledge and Security for Humanity. [37] J. Horgan, 1996. The end of science. Reading, MA.: Addison-Wesley

[38] N. Howard, 1994. Drama theory and its relation to game theory. part 1: Dramatic resolution vs. rational solution. Group Decision and Negotiation. 3 (2): 187- 206.

[39] M.C. Jackson, 2001. Critical systems thinking and practice. European Journal of Operational Research. 128 (2): 233-244.

[40] M. Jamshidi, (Ed). (2009). Systems of systems engineering. New Jersey: John Wiley \& Sons

[41] M. Johns, 2006. Deception and trust in complex semi-competitive environments. PhD. diss., University of Pennsylvania.

[42] S. Krasner, D. Stephen, C. Pascual, Addressing state failure, Foreign Affairs, 84, (2005), 153-163.

[43] D. Kilcullen, 2006. “Twenty-Eight Articles”: fundamentals of company-level counterinsurgency, Military Review. May-June.

[44] J.G. Kim, 2006. The Nature and Timing of Political Stabilization. PhD. diss., University of Michigan.

[45]G. King, W. Lowe. 2003 “An Automated Information Extraction Tool For International Conflict Data with Performance as Good as Human Coders”, International Organization, Vol. 57, No. 03 (July): pp. 617-642.

[46] A. Kott, P. Carpac, (2007). COMPOEX technology to assist leaders in planning and executing campaigns in complex operational environments. Proc $12^{\text {th }}$ Inter'l Command and Control Research and Technology Symposium “Adapting C2 to the $21^{\text {st }}$ Century”, Newport, VA. [47] C. Kottak, 2005. Window on humanity: A concise introduction to general anthropology. New York: McGraw Hill.

[48] T.S. Kuhn, 1970. The structure of scientific revolutions. Chicago: University of Chicago Press.

[49] D.R. Layder, 1998. Sociological practice: Linking theory and social research. UK: Sage Publications.

[50] N. Machiavelli, 1988. The Prince. Ed. Q. Skinner and R. Price. Cambridge: Cambridge University Press. 
Intelligent Decision Technologies Journal (v.4, n.1, 2010, pp. 51-74)

[51] R. Mason, I. Mitroff, 1973. A program for research on management information systems. Management Science, 19 (5): 475- 487.

[52] I. McCulloh, K.M. Carley, (2008). Detecting Change in Human Social Behavior

Simulation. Carnegie Mellon Univ, Inst. Software Research, Tech Report CMU-ISR-08-135.

[53] S. Miles, 2001. Social theory in the real world. London, CA, New Delhi: Sage

Publications.

[54] A. Ortony, G.L. Clore, and A. Collins, 1988. The cognitive structure of emotions.

Cambridge: Cambridge University Press.

[55] B. Osman, W.F. Ormsby, Network-centric military system architecture assessment

methodology. Int. J. System of Systems Engineering, 1, (2008), 271-292.

[57] D.H. Patraeus, J.F. Amos, and J.A. Nagl, 2007. The U.S. Army/Marine corps

counterinsurgency field manual (FM 3-24). Chicago: University of Chicago Press.

[58] K. Popper, 1965. Conjectures and refutations: The growth of scientific knowledge, New

York: Basic Books, Inc.

[59] A. Przeworski, M.E. Alvarez, JA. Cheibub, F. Limongi, Fernando. 2000. Democracy and development. Cambridge: Cambridge University Press.

[60] H.W.J. Rittel, M.M. Webber, 1973. Dilemmas in a general theory of planning. Policy

Sciences. 4 (2): 155-169.

[61] A.P. Sage, S. Biemer, Processes for system family architecting, design, and integration.

IEEE Systems Journal, 1, (2007), 5-16.

[62] Schrodt, PA, Davis, S.G., Weddle, J.L. 1994. Political science: KEDS-a program for the machine coding of event data. Social Science Computer Review 12(3): 561-588.

[63] B.G. Silverman, R. Might, R. Dubois, H. Shin, and M. Johns, 2001. Toward a human behavior modeling anthology for developing synthetic agents. Proceedings of the tenth conference on Computer Generated Forces and Behavioral Representation - SISO, May 15 - 17, in Norfolk VA.

[64] B.G. Silverman, R. Rees, et al. 2005. Athena’s Prism: A diplomatic strategy role playing game for generating ideas and exploring alternatives. Presented at the international conference on Intelligence Analysis, Mitre in MacLean, VA.

[65] B.G. Silverman, M. Johns, J. Cornwell, and K. O’Brien, 2006a. Human behavior models for agents in simulators and games: part I - enabling science with PMFserv. MIT Press

Journals- Presence. 15 (2): 139-162.

[66] B.G. Silverman, K. O’Brien, and J.Cornwell, 2006b. Human behavior models for agents in simulators and games: part II - gamebot engineering with PMFserv. MIT Press Journals Presence. 15 (2): 163-185.

[67] B.G. Silverman, G.K. Bharathy, B. Nye, and R.J. Eidelson, 2007. Modeling factions for 'effects based operations': part I - leaders and followers. J. Computational \& Mathematical Organization Theory. 13 (4): $379-406$.

[68] B.G. Silverman, G.K. Bharathy, B. Nye, Benjamin, and T. Smith, 2008. Modeling factions for 'effects based operations': part II - behavioral game theory”, J. Computational \& Mathematical Organization Theory. 14 (2): 120-155.

[69] E.A. Singer, 1959. Experience and Reflection, Philadelphia: University of Pennsylvania Press.

[70] A. Sousa-Poza, S. Kovacic, and C. Keating, 2008. System of systems engineering: an emerging multidiscipline. Int. J. Systems of Systems Engineering. 1 (1)/(2): 1 - 17.

[71] R. Swedberg, 2001. Sociology and Game Theory, J. Theory and Sociology, 
30 (3): 301-335.

[72] R. Sun, 2006. Cognition and Multi-Agent Action, Cambridge: Cambridge Univ. Press.

[73] P. Tetlock, 2005. Expert political judgment: How good is it? How can we know? Princeton: Princeton University Press.

[74] E. Waltz, (2008). Situation analysis and collaborative planning for complex operations, Proceedings of the $13^{\text {th }}$ ICCRTS “C2 for Complex Endeavors", Bellevue, WA.

[75] A. Wendt, 1999. Social Theory of International Politics. Cambridge: Cambridge University Press.

[76] B. White, 2008. Systems science: Deepening our understanding of the theory and practice of systems engineering. Insight: INCOSE, 11 (1).

[77] C. Wight, 2006. "Realism, science and emancipation": Philosophy and social science. Kathryn Dean, Jonathan Joseph, and John Michael Roberts, 37 - 64. New York: Palgrave MacMillan.

[78] G.L. Zacharias, J. MacMillan, and S.B. Van Hemel, (Eds.) (2008). Behavior Modeling and Simulation: From Individuals to Societies. National Academies Press, Washington DC. 